Article

\title{
Decomposition of Industrial Electricity Efficiency and Electricity-Saving Potential of Special Economic Zones in China Considering the Heterogeneity of Administrative Hierarchy and Regional Location
}

\author{
Jianmin You ${ }^{1,2}$, Xiqiang Chen ${ }^{1}$ and Jindao Chen ${ }^{1, *}$ \\ 1 School of Economics and Statistics, Guangzhou University, Guangzhou 510006, China; \\ jianminyou@foxmail.com (J.Y.); xdchenxq@163.com (X.C.) \\ 2 Guizhou Institute of Local Modernized Governance, Guizhou Academy of Social Science, \\ Guiyang 550002, China \\ * Correspondence: jindaochen@gzhu.edu.cn
}

\section{check for}

updates

Citation: You, J.; Chen, X.; Chen, J. Decomposition of Industrial

Electricity Efficiency and

Electricity-Saving Potential of

Special Economic Zones in China

Considering the Heterogeneity of

Administrative Hierarchy and

Regional Location. Energies 2021, 14,

5468. https://doi.org/10.3390/

en14175468

Academic Editor: Oscar Barambones

Received: 5 August 2021

Accepted: 29 August 2021

Published: 2 September 2021

Publisher's Note: MDPI stays neutral with regard to jurisdictional claims in published maps and institutional affiliations.

Copyright: (c) 2021 by the authors. Licensee MDPI, Basel, Switzerland. This article is an open access article distributed under the terms and conditions of the Creative Commons Attribution (CC BY) license (https:/ / creativecommons.org/licenses/by/ $4.0 /)$.

\begin{abstract}
Special Economic Zones (SEZs), an important engine of industrial economic development in China, consume large amounts of energy resources and emit considerable CO2. However, existing research pays little attention to industrial energy usage in SEZs and ignores the heterogeneity of administrative hierarchy and regional location. Considering the dual heterogeneity, this study proposes an improved two-dimension and two-level meta-frontier data envelopment analytical model to decompose the industrial electricity efficiency (IEE) and electricity-saving potential of SEZs in Guizhou Province, China, based on 4-year field survey data (2016-2019). Results show that the IEE rankings of three administrative hierarchies within SEZs are provincial administration SEZs, county administration SEZs, and municipality administration SEZs. The SEZs located in energy resourcerich areas and better ecological environmental areas have higher IEE than those in resource-poor areas and ecology fragile areas, respectively. This study can provide reference for policymakers to formulate effective policies for improving the electricity use efficiency of SEZs in China.
\end{abstract}

Keywords: meta-frontier DEA; special economic zone; industrial electricity efficiency; electricity-saving potential

\section{Introduction}

Global warming caused by the continuous rise of carbon dioxide concentration in the atmosphere has become an increasingly important issue to the international community [1,2] China, one of the world's largest carbon emitter, emitted 105.59 million tons of carbon dioxide in 2019 , of which the industrial sector accounted for $38.92 \%$ due to the substantial amount of energy consumption $[3,4]$. The industrial sector is the driving force behind the reduction of energy consumption and carbon emissions in China [5,6]. In response to global warming, China committed that carbon dioxide emissions will peak before 2030 and achieve carbon neutrality before 2060, which will pose a severe challenge to industrial development and energy use.

Special Economic Zones (SEZs), the important carrier of industrial economic development, are playing an extremely important role in China's economic development $[7,8]$. To date, China has set up 2543 SEZs, including 1991 provincial-level SEZs and 252 state-level SEZs [9]. The 252 state-level SEZs alone created an industrial added value of 6.10 trillion RMB in 2017, accounting for $21.79 \%$ of the national industrial added value [10]. The Special Economic Zones have become the important engine driving the local industrial development and economic growth.

Meanwhile, SEZs consume a considerable amount of energy resources, which are dominated by coal and other fossil fuels in China, leading to a considerable number of 
carbon emissions associated with energy consumption in SEZs. Guo et al. [11] reported that the carbon emission in the state-level SEZs was 1223 million tons, accounting for $10.8 \%$ of the national total emissions. The Special Economic Zones have become a focus area with considerable energy consumption and carbon emissions that make China face great pressure on environmental issues. Therefore, the industrial energy efficiency in SEZs must be analyzed to reduce China's energy consumption and carbon emissions.

The industrial energy efficiency in SEZs is significantly influenced by the dual heterogeneity of regional location and administrative hierarchy. In terms of regional location, the site selection of SEZs is based on certain factors, such as geographic location, resource endowment, industrial conditions, and human capital. These factors vary in different regions and greatly affect energy efficiency. The technological gap between the less developed and the developed regions will lead to great differences of energy efficiency [12,13]. Each region with distinctive industries due to various resource endowments has different energy efficiency $[14,15]$. In terms of administrative hierarchy, the SEZs have three different administrative hierarchies, including provincial, municipal, and county SEZs. Although China has two main categories of SEZs, namely, state-level and province-level SEZs, the SEZs are located in cities with different administrative hierarchies and under the jurisdiction of provincial, municipal, and county governments. The Special Economic Zones are urban systems with high cluster intensity of industries and population [16]. The higher the administrative hierarchy of cities, the stronger the ability of spatial allocation and acquisition of resources of cities $[17,18]$. For example, the SEZs with different administrative levels can obtain different public financial funds. The SEZs with more funds will give more subsidies to industrial enterprises, which will greatly reduce the energy cost of industrial enterprises, affecting the energy transformation and energy efficiency [19]. The technological level of the industrial enterprises in the SEZs with different administrative levels is different. The higher the technological level of the SEZs affects the energy utilization level of industrial enterprises which will also be improved, which will affect the energy efficiency of the SEZs. Accordingly, the energy efficiency of SEZs at different administrative hierarchies substantially varies. Thus, the dual heterogeneity should be considered when formulating measures for energy conservation and carbon emission reduction in SEZs.

In recent years, researchers have shown an increased interest in China's SEZs. However, research on energy usage of SEZs is scarce. Moreover, existing literature on SEZs has two major deficiencies. On the one hand, most scholars study either SEZs at the same administrative hierarchy or a single SEZ through field research, neglecting the administrative hierarchy and regional location heterogeneity among SEZs. On the other hand, previous literature mainly focuses on state-level SEZs, while few scholars study province-level SEZs due to the paucity of data.

On this basis, this study aims to propose an improved two-dimension and twolevel meta-frontier data envelopment analytical (DEA) model to measure and decompose industrial electricity efficiency (IEE) and electricity-saving potential (IEP) of SEZs from the perspective of dual heterogeneity based on the data collected from a 4-year field survey. The contributions of this work have mainly three points. First, this work considers the influence of not only administrative hierarchy heterogeneity on SEZs but also regional location heterogeneity on SEZs. This work provides a paradigm for studying the energy efficiency of SEZs in China. Second, this work evaluates the energy efficiency in the SEZs by using the data of a 4-year field survey. The energy data for SEZs, which are not regarded as administrative areas in China, have not been officially collected and published. Third, this work further decomposes the dynamic change of the IEE of SEZs from the two dimensions of administrative hierarchy and regional location. From the dimension of administrative hierarchy, the dynamic change is decomposed into hierarchy efficiency change $(\mathrm{HECH})$, technological progress change (TECH), and management efficiency change (MECH). From the dimension of regional location, the dynamic change is decomposed into regional efficiency change (RECH), TECH, and MECH. 
The remainder of this paper is organized as follows. Section 2 reviews relevant literature. Section 3 introduces research methods and describes data. Section 4 reports and discusses the empirical results. Section 5 concludes the research and proposes policy recommendations.

\section{Literature Review}

\subsection{Special Economic Zones}

Existing literature mainly focuses on policy impact and operational efficiency evaluation of SEZs. In terms of policy impact, most scholars regard SEZs as a specific regional policy or industrial policy and explore the policy's influence on employment, income, productivity, and spillover effect. Busso et al. [20] assessed the impact of the federal urban empowerment zone program on the employment and wages of zone neighborhoods and local workers by using confidential microdata. Zheng et al. [21] explored the effects of development zones on the economic development of host regions by using macro-level and meso-level analyses. Qiangmin et al. [22] proved the productivity advantages of producer service industry in the SEZs. Alkon [23] evaluated the effects of SEZs on the basis of the crucial role of political economy incentive structures facing local politicians.

In terms of SEZ operational efficiency evaluation, existing literature mainly investigates innovation efficiency, comprehensive development efficiency, and input-output efficiency of production factors in state-level SEZs. Yan et al. [24] constructed an index system for measuring the innovation level of China's state-level high-tech zones and evaluated their innovation efficiency. Wang et al. [25] evaluated the operational efficiency of 27 state-level high-tech industrial development zones in China on the basis of the DEA method. Zhang et al. [26] evaluated the input efficiency of production factors of 13 statelevel economic and technological development zones in Jiangxi Province by using an empirical analysis based on Malmquist index and dynamic panel models.

However, little literature analyzes the energy efficiency of SEZs, especially the IEE of SEZs, and the existing literature mainly focuses on the state-level SEZs.

\subsection{Electricity Efficiency Measurement}

The three measurement methods for the electricity efficiency include single-factor index analysis, Stochastic Frontier Analysis (SFA), and traditional DEA. First, some scholars use single-factor index to study electricity efficiency. Liddle, Inglesi-Lotz and Blignaut, Inglesi-Lotz and Blignaut, and Davies [27-30] measured and analyzed the electricity efficiency of a country or region by using electricity intensity (ratio between electricity consumption and economic output). Second, many scholars used the SFA approach to measure electricity efficiency. Lin and Zhu [31] took total energy demand as a function of income level, population, industrial structure, urbanization level, energy price, energy structure and other factors, and used the SFA method to measure the electricity efficiency in China. Broadstock et al., Andor et al., and Twerefou and Abeney [32-34] estimated the residential electricity efficiency in China, the United States, and Ghana by adopting the SFA method. Third, a few scholars employed the traditional DEA method to measure the total factor electricity efficiency. Özkara and Atak [35] used electricity consumption instead of energy data to investigate the power efficiency and electricity-saving potential of Turkey's manufacturing region from the perspective of total factor production. He et al. [36] took human resources, capital, and power consumption as input factors; GDP as expected input, and carbon emissions as non-expected input. They also adopted the epsilon-based measure (EBM) model from the perspective of total factors to measure and evaluate the electricity efficiency of 30 provinces in China from 2006 to 2015. Inglesi-Lotz and Blignaut [29] proposed a benchmarking and trading system to reduce South Africa's electricity intensity and improve efficiency in an effort to reduce emissions in the country.

However, the above-mentioned three methods fail to reflect the difference of production technological level in the SEZs with different administrative hierarchies and regional locations. The different administrative hierarchies and regional locations cause varying production technological frontiers in the SEZs. Evaluating the electricity efficiency without 
the consideration of administrative hierarchy and regional heterogeneity could result in efficiency deviation. O'Donnell et al. [37] proposed a meta-frontier approach to solve the defects of traditional DEA methods and constructed a formal theoretical framework of meta-frontier and group frontier. Wang et al., Feng et al., and Chen et al. [14,38,39] constructed a multilevel meta-frontier DEA model to measure China's energy efficiency and electricity-saving potential from the perspective of regional and industrial heterogeneities.

\section{Materials and Methods}

This section consists of four parts. First, we chose Guizhou SEZs (G-SEZs) as a case study. Second, we proposed a two-dimension and two-level meta-frontier DEA method. Third, we decomposed the dynamic changes of G-SEZs' IEE considering the heterogeneity of administrative hierarchy and regional location by using the Malmquist productivity index. Finally, we presented the collection and processing of samples and data.

\subsection{Case Study System: Guizhou SEZs}

This research selected Guizhou Province, China, as a case study. Guizhou is in southwest China and has established 73 SEZs since 1992. After approximately 40 years of development, the industrial added value of G-SEZs has reached 235.012 billion yuan in 2019 , accounting for more than 50\% of the industrial added value of Guizhou Province. The energy consumption in G-SEZs also rapidly increased with the rapid increase in industrial added value. During 2016-2019, the average annual industrial electricity consumption in G-SEZs reached 40 billion $\mathrm{kWh}$, accounting for more than $40 \%$ of the total consumption in Guizhou. Guizhou, known as the "Southwest Coal Sea", has 49.728 billion tons of coal reserves and generates more than $60 \%$ of electricity from coal [3]. The electricity supply structure of G-SEZs is dominated by coal power generation due to the abundant coal resources, thereby increasing the carbon emission intensity of industrial electricity consumption in G-SEZs.

The heterogeneity of administrative hierarchy and regional location of G-SEZs is obvious, which provides a suitable sample for studying the influence of the dual heterogeneity on IEE of SEZ. Guizhou has nine prefectures and presents different regional characteristics, such as energy and resource-rich area, concentrated contiguous poverty area, ecological area, and traditional industrial area. According to the administrative hierarchy, G-SEZs can be divided into provincial administration SEZs (P-SEZs), municipality administration SEZs (M-SEZs), and county administration SEZs (C-SEZs), as shown in Figure 1.

\subsection{Two-Dimension and Two-Level Meta-Frontier DEA}

DEA is a nonparametric linear programming method proposed by Charnes et al. [40] to measure the efficiency of decision-making units (DMUs). This work constructs a DEAbased measurement method for IEE from the perspective of total factor framework to accurately estimate IEE of SEZs, in accordance with Feng et al., $\mathrm{Hu}$ and Wang, and Wang et al. $[14,41,42]$. This concept can be expressed as follows:

$$
\begin{gathered}
\mathrm{EE}=\min \lambda \\
\text { s.t. }\left\{\begin{array}{l}
\sum_{k=1}^{K} Z_{k} x_{k} \leq x \\
\sum_{k=1}^{K} Z_{k} x e_{k} \leq \lambda e \\
\sum_{k=1}^{K} Z_{k} y_{k} \geq y \\
\lambda \geq 0 ; Z_{k} \geq 0 ; k=1,2 \cdots K
\end{array}\right.
\end{gathered}
$$

where $x, e$, and $y$ represent non-energy input factors, industrial electricity input, and industrial output, respectively; $\lambda$ represents total-factor IEE; $Z_{k}$ is the intensity variable, and $K$ is the number of DMUs. 
We introduce a meta-frontier production function model to measure the technical gap ratio (TGR) between the group frontier and the meta-frontier following Battese et al. and Zhou et al. $[43,44]$. This task is conducted to analyze the influence of administrative hierarchy and regional location heterogeneity on SEZs' IEE. The groups of SEZs at different administrative hierarchies and those of SEZs in diverse regions have varying production technological frontiers, respectively. Unlike group frontiers, the meta-frontier production function model is constructed on the basis of the assumption that all SEZs in Guizhou have homogeneous production technology. We can decompose the SEZs' IEE from two dimensions, namely, administrative hierarchy and regional location, by using the relationship between meta-frontier and group frontier.

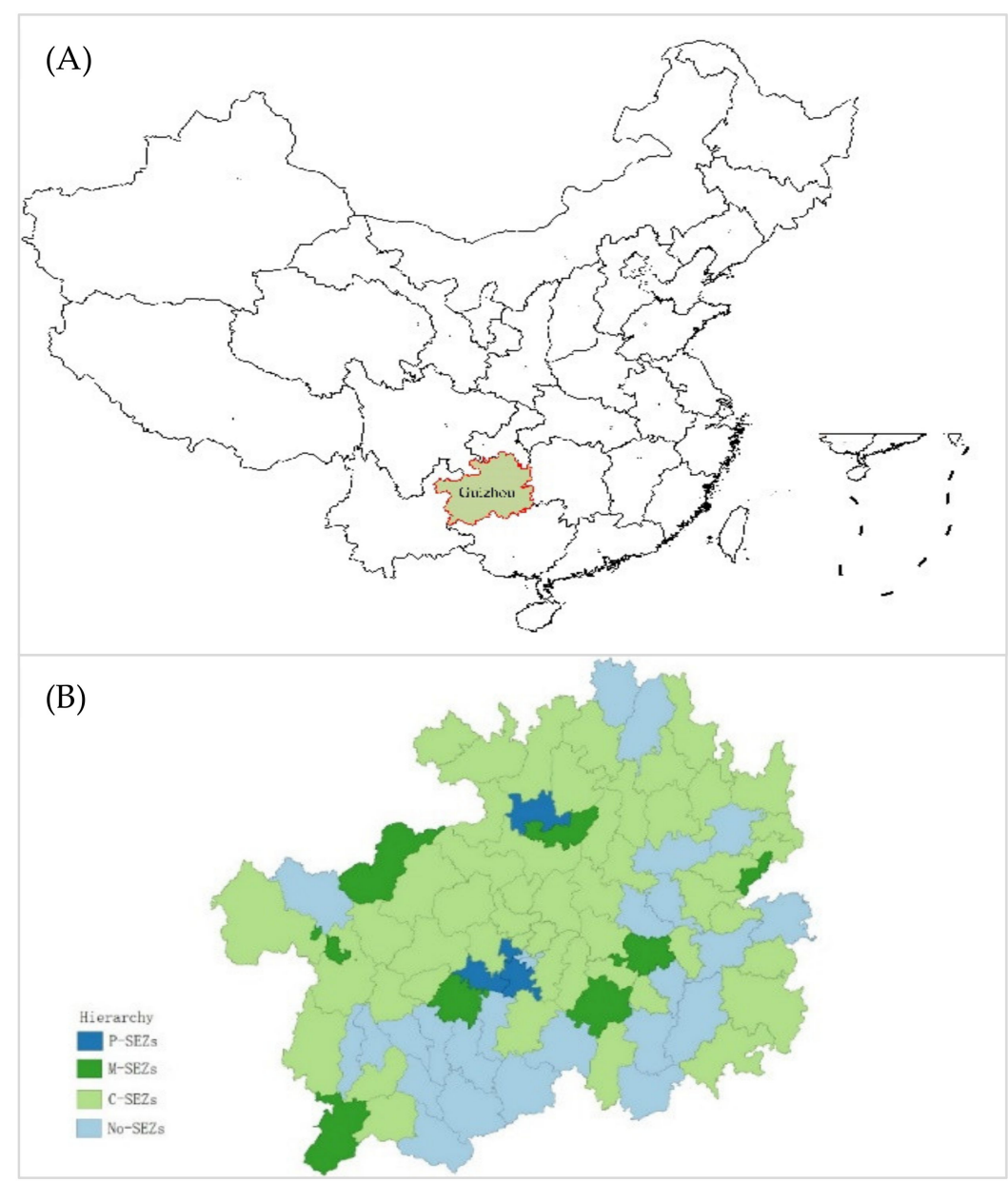

Figure 1. The location of Guizhou Province in China (A) and different administration hierarchy SEZs in Guizhou (B).

From the perspective of administrative hierarchy, the IEE can be divided into two parts, including administrative hierarchy efficiency (HE) and management efficiency (ME). From the dimension of regional location, the IEE can be decomposed into two aspects, namely, RE and ME. We also decomposed the electricity inefficiency of SEZs in different groups under meta-frontier from the dimensions of administrative hierarchy and regional location to identify the real source of SEZs' electricity inefficiency. In the dimension of administrative hierarchy, the electricity inefficiency can be decomposed into administrative hierarchy gap inefficiency and group frontier management inefficiency (MI). In the regional location dimension, the electricity inefficiency is decomposed into regional gap inefficiency and group frontier MI. The specific decomposition is as follows.

First, we decompose IEE and electricity inefficiency from the administrative hierarchy. G-SEZs are mainly divided into three hierarchies: P-SEZs, M-SEZs, and C-SEZs. The G- 
SEZs are divided into three groups according to the difference of administrative hierarchy. Each group consists of several technology sets under the same production technological level. The decomposition is described in Figure 2.

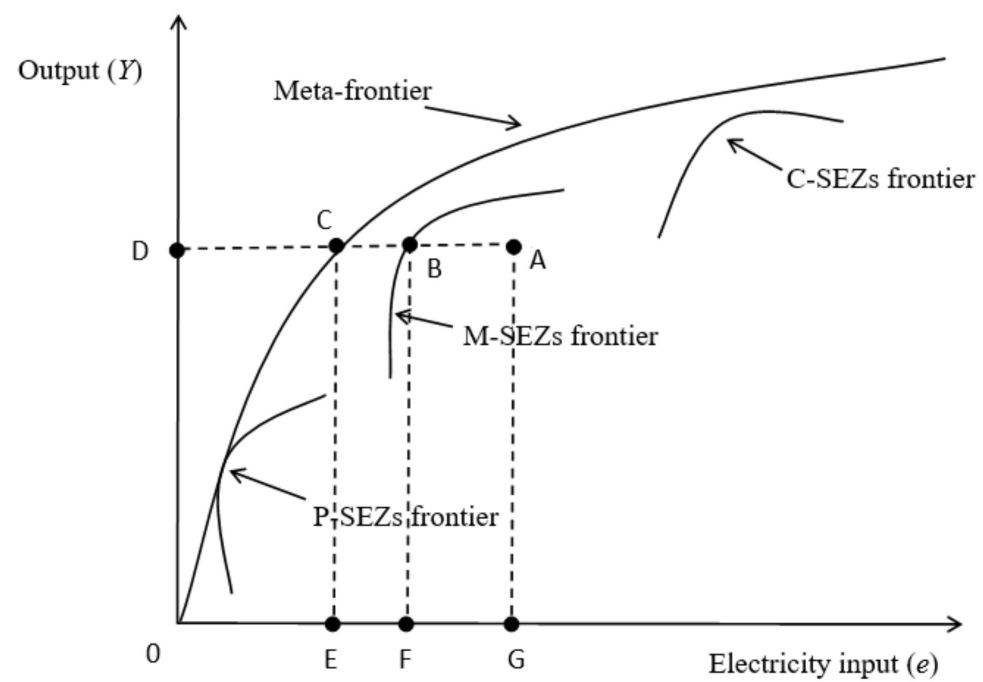

Figure 2. The administrative hierarchy meta-frontier.

We assume that $\lambda^{m}$ and $\lambda^{h}$ represent the IEE under meta-frontier and administrative hierarchy frontier, respectively, and they can be defined as follows for DMU $A$ :

$$
\lambda^{m}=\frac{\mathrm{OE}}{\mathrm{OG}} ; \lambda^{h}=\frac{\mathrm{OE}+\mathrm{EF}}{\mathrm{OG}}=\frac{\mathrm{OF}}{\mathrm{OG}}
$$

The distance between group frontier and meta-frontier is different for each administrative hierarchy SEZ, which reflects the production technical gap. Specifically, the distance represents the contribution of administrative hierarchy to SEZs' IEE, that is, the HE, which can be expressed by the following formula:

$$
\mathrm{HE}=\mathrm{TGR}^{m h}=\frac{\lambda^{m}}{\lambda^{h}}
$$

IEE and ME can be further represented as follows by combining Equations (2) and (3):

$$
\mathrm{ME}=\lambda^{h} \leq 1, \mathrm{IEE}=\lambda^{m}=\mathrm{HE} \times \mathrm{ME}
$$

The counterpart of IEE is industrial electricity inefficiency (IEI). The total electricity inefficiency for DMU $A$ can be measured by EG/OG. FG/OG denotes the gap between DMU $A$ and M-SEZ frontier; this is a loss of IEE due to DMU $A$ management failure under M-SEZ frontier technology. EF/OG can be measured as IEE loss caused by administrative hierarchy heterogeneity. We used IEI, HI, and MI to represent the total electricity inefficiency, administrative hierarchy inefficiency, and MI, respectively. These three inefficiencies can be measured by the following formula:

$$
\mathrm{IEI}=\mathrm{HI}+\mathrm{MI} ; \mathrm{HI}=\lambda^{h}-\lambda^{m} ; \mathrm{MI}=1-\lambda^{h}
$$

In Figure 2, AC represents the total electricity-saving space of DMU $A, \mathrm{AB}$ indicates the electricity-saving space that can be reduced by SEZs to improve its own ME, and BC denotes the IEE gap between group frontier and meta-frontier caused by administrative hierarchy. The electricity consumption of SEZs is determined, the corresponding total IEP, 
hierarchy saving potential (HP), and management saving potential (MP) can be calculated using the following formula:

$$
\mathrm{IEP}=\mathrm{HP}+\mathrm{MP} ; \mathrm{HP}=\left(\lambda^{h}-\lambda^{m}\right) \times e ; \mathrm{MP}=\left(1-\lambda^{h}\right) \times e
$$

The administrative hierarchy factor has a great influence on the SEZs' IEE. In the above analysis, we incorporate the administrative hierarchy into the analytical framework of the meta-frontier production technology and decompose IEE/IEI/IEP into three parts: $\mathrm{HE} / \mathrm{ME}, \mathrm{HI} / \mathrm{MI}$, and HP/MP.

Second, we decompose the regional factors from the regional angle of SEZs to investigate their influence on IEE and IEP. The process of decomposition is the same from the perspective of administrative hierarchy. Guizhou has nine prefecture-level cities, each of them has different economic foundation, resource endowment, population, and scientific and technological levels. In view of this situation, we divided all SEZs into nine groups and incorporated each group frontier into meta-frontier for research and analysis (Figure 3). The nine groups of SEZs are Bijie-SEZs (BJ-SEZs), Guiyang (GY-SEZs), Qiannan-SEZs (QN-SEZs), Liupanshui-SEZs (LPS-SEZs), Qianxinan-SEZs (QXN-SEZs), Tongren-SEZs (TR-SEZs), Anshun-SEZs (AS-SEZs), Qiandongnan-SEZs (QDN-SEZs), and Zunyi-SEZs (ZY-SEZs).

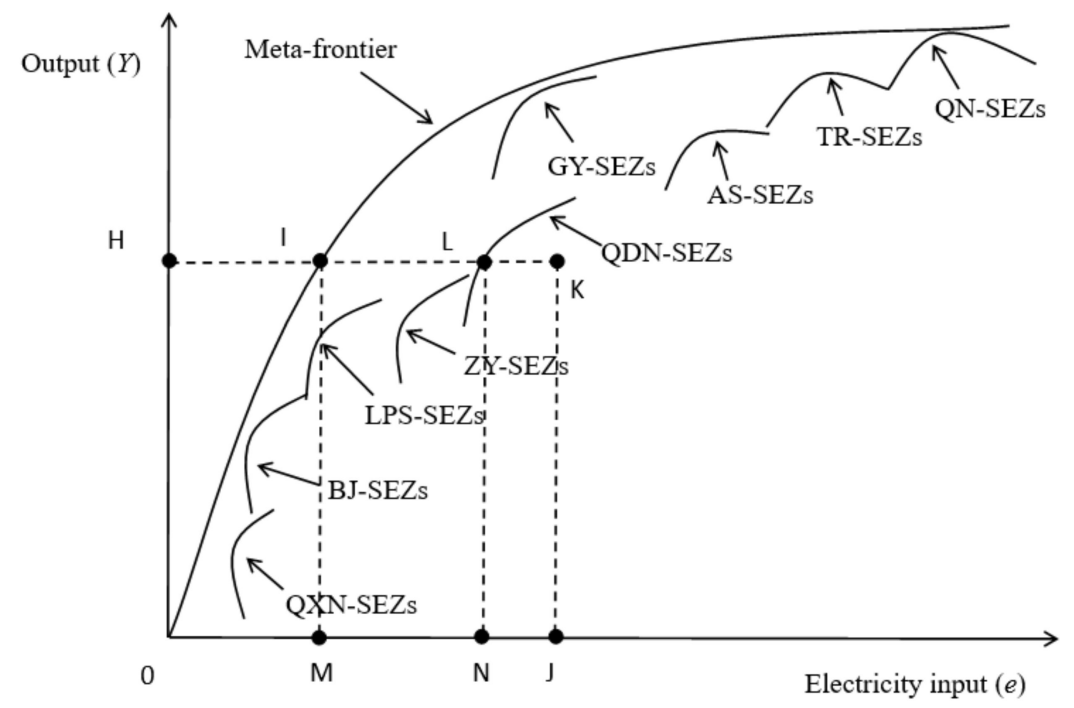

Figure 3. The regional meta-frontier.

$\lambda^{m}$ is still used to represent the IEE under meta-frontier. $\lambda^{r}$ represents the IEE under regional frontier. In Figure 3, for DMU $K, \lambda^{m}$, and $\lambda^{r}$ can be defined using the following formula:

$$
\lambda^{m}=\frac{\mathrm{OM}}{\mathrm{OJ}} ; \lambda^{r}=\frac{\mathrm{OM}+\mathrm{MN}}{\mathrm{OJ}}=\frac{\mathrm{ON}}{\mathrm{OJ}}
$$

The production technology frontier of each SEZ group in different regions varies, leading to their diverse distances from the meta-frontier. This distance can be calculated using the TGR. Given that different distances are caused by regional factors, we define it as $\mathrm{RE}$. The formula is as follows:

$$
\mathrm{RE}=\mathrm{TGR}^{m r}=\frac{\lambda^{m}}{\lambda^{r}}
$$

From a regional location perspective, IEE and ME can be further represented as follows by combining Equations (7) and (8):

$$
\mathrm{ME}=\lambda^{r} \leq 1 ; \mathrm{IEE}=\lambda^{m}=\mathrm{RE} \times \mathrm{ME}
$$


Next, we incorporate regional factors into the analytical framework to analyze the IEE loss. The total IEI for DMU K can be measured by MJ/OJ. NJ/OJ denotes the gap between DMU $K$ and QDN-SEZ frontier, representing ME loss of DMU $K$ under the regional frontier. $\mathrm{MN} / \mathrm{OJ}$ can be the measured as IEE loss caused by regional location heterogeneity. We used RI to represent the regional location inefficiency. The relationship and measurement among IEI, RI, and MI are as follows:

$$
\mathrm{IEI}=\mathrm{RI}+\mathrm{MI} ; \mathrm{RI}=\lambda^{r}-\lambda^{m} ; \mathrm{MI}=1-\lambda^{r}
$$

After the inefficiency of SEZs in the regions are evaluated, we further measured their IEP. MJ represents the total electricity-saving space of DMU K, NJ denotes the electricitysaving space of each SEZ in the regional distribution by improving its own ME. MN represents the IEE gap between regional frontier and meta-frontier. The formula is transformed as follows:

$$
\mathrm{IEP}=\mathrm{RP}+\mathrm{MP} ; \mathrm{RP}=\left(\lambda^{r}-\lambda^{m}\right) \times e ; \mathrm{MP}=\left(1-\lambda^{r}\right) \times e
$$

We successfully incorporated regional factors into the study of IEE and IEP from another new perspective through the above decomposition. This initiative will help us understand the important role of regional location in the development of SEZs.

\subsection{Dynamic Change Decomposition of IEE}

Färe et al. [45] proposed the Malmquist productivity index, which is used to measure changes in the performance of each DMU over two periods. However, the Malmquist productivity index is based on the contemporaneous productivity possibility set; however, it has some drawbacks, that is, non-cyclic and linear programming are not feasible. Pastor and Lovell [46] regarded the data of all periods as the productivity possible set to solve these weaknesses. Then, they proposed a Global Malmquist (GM) index. We constructed a GM index following An et al. [47] to explore the dynamic changes of SEZs' IEE.

Prior to the construction of GM, two benchmark technologies need to be defined: contemporaneous and global benchmark technologies.

The contemporaneous benchmark technology is defined as follows:

$$
\mathrm{P}^{\mathrm{t}}\left(x^{\mathrm{t}}, e^{\mathrm{t}}\right)=\left\{y^{\mathrm{t}} \mid\left(x^{\mathrm{t}}, e^{\mathrm{t}}\right) \text { canproduce } y^{\mathrm{t}}\right\} \mathrm{t}=1, \cdots, \mathrm{T}
$$

where superscript $\mathrm{t}$ stands for time, and $\mathrm{P}^{\mathrm{t}}$ presents the contemporaneous production possibility of period $t$ and consists only of observations at the time.

The global benchmark technology is defined as follows:

$$
\mathrm{P}^{\mathrm{G}}=\mathrm{P}^{1} \cup \mathrm{P}^{2}, \cdots, \cup \mathrm{P}^{\mathrm{T}}
$$

where superscript $\mathrm{T}$ indicates that the data has $\mathrm{T}$ periods. This global benchmark technology envelopes all contemporaneous benchmark technologies. On this basis, we can establish a single reference benchmark by utilizing panel data containing input and output from SEZs.

The GM reflects the change of IEE from $t$ to $t+1$ period, which is defined in this work as follows:

$$
\mathrm{GM}^{\mathrm{t}, \mathrm{t}+1}=\frac{\lambda^{\mathrm{G}}\left(x^{\mathrm{t}+1}, e^{\mathrm{t}+1}, y^{\mathrm{t}+1} \mid \mathrm{CRS}\right)}{\lambda^{\mathrm{G}}\left(x^{\mathrm{t}}, e^{\mathrm{t}}, y^{\mathrm{t}} \mid \mathrm{CRS}\right)}
$$

where $\lambda^{\mathrm{G}}\left(x^{\mathrm{t}+1}, e^{\mathrm{t}+1}, y^{\mathrm{t}+1} \mid \mathrm{CRS}\right)$ and $\lambda^{\mathrm{G}}\left(x^{\mathrm{t}}, e^{\mathrm{t}}, y^{\mathrm{t}} \mid \mathrm{CRS}\right)$ represent the IEE of DMU in periods $t+1$ and $t$ under the global benchmark productivity possibility set, respectively, and take the assumption of constant return to scale as the premise. 
The GM can also be decomposed into components of IEE, as follows:

$$
\begin{gathered}
\mathrm{GM}^{\mathrm{t}, \mathrm{t}+1}=\left[\frac{\lambda^{\mathrm{G}}\left(x^{\mathrm{t}+1}, e^{\mathrm{t}+1}, y^{\mathrm{t}+1} \mid \mathrm{CRS}\right)}{\lambda^{\mathrm{t}+1}\left(x^{\mathrm{t}+1}, e^{\mathrm{t}+1}, y^{\mathrm{t}+1} \mid \mathrm{CRS}\right)} / \frac{\lambda^{\mathrm{G}}\left(x^{\mathrm{t}}, e^{\mathrm{t}}, y^{\mathrm{t}} \mid \mathrm{CRS}\right)}{\lambda^{\mathrm{t}}\left(x^{\mathrm{t}}, e^{\mathrm{t}}, y^{\mathrm{t}} \mid \mathrm{CRS}\right)}\right] \times \\
\frac{\lambda^{\mathrm{t}}\left(x^{\mathrm{t}+1}, e^{\mathrm{t}+1}, y^{\mathrm{t}+1} \mid \mathrm{CRS}\right)}{\lambda^{\mathrm{t}}\left(x^{\mathrm{t}}, \mathrm{e}^{\mathrm{t}}, y^{\mathrm{t}} \mid \mathrm{CRS}\right)}=\mathrm{GTCH}^{\mathrm{t}, \mathrm{t}+1} \times \mathrm{TECH}^{\mathrm{t}, \mathrm{t}+1}
\end{gathered}
$$

where $\lambda^{\mathrm{t}+1}\left(x^{\mathrm{t}+1}, e^{\mathrm{t}+1}, y^{\mathrm{t}+1} \mid \mathrm{CRS}\right)$ and $\lambda^{\mathrm{t}}\left(x^{\mathrm{t}}, e^{\mathrm{t}}, y^{\mathrm{t}} \mid \mathrm{CRS}\right)$ denote the SEZs' IEE in periods $\mathrm{t}+1$ and $t$ under benchmarks $\mathrm{P}^{\mathrm{t}+1}$ and $\mathrm{P}^{\mathrm{t}}$, respectively. According to Equation (15), the GM between periods $t$ and $t+1$ is divided into two parts: technical efficiency change GTCH ${ }^{t, t+1}$ and technical progress change $\mathrm{TECH}^{\mathrm{t}, \mathrm{t}+1}$. The $\mathrm{GTCH}^{\mathrm{t}, \mathrm{t}+1}$ and $\mathrm{TECH}^{\mathrm{t}, \mathrm{t}+1}$ are greater than (or equal to) 1, representing technical efficiency improvement and technical progress (or technical efficiency decline and technical backwardness), respectively.

$\mathrm{TECH}^{\mathrm{t}, \mathrm{t}+1}$ can be further decomposed from the two dimensions of SEZ administrative hierarchy and region by combining Equations (4) and (9). The decomposition equation is as follows:

Decomposition for SEZ administrative hierarchy dimension:

$$
\mathrm{TECH}^{\mathrm{t}, \mathrm{t}+1}=\mathrm{HECH}^{\mathrm{t}, \mathrm{t}+1} \times \mathrm{MECH}^{\mathrm{t}, \mathrm{t}+1}
$$

where $\mathrm{HECH}^{\mathrm{t}, \mathrm{t}+1}$ and $\mathrm{MECH}^{\mathrm{t}, \mathrm{t}+1}$ represent the change of SEZ HE and MECH from periods $\mathrm{t}$ to $\mathrm{t}+1$, respectively.

Decomposition for SEZ regional dimension:

$$
\mathrm{TECH}^{\mathrm{t}, \mathrm{t}+1}=\mathrm{RECH}^{\mathrm{t}, \mathrm{t}+1} \times \mathrm{MECH}^{\mathrm{t}, \mathrm{t}+1}
$$

where $\mathrm{RECH}^{\mathrm{t}, \mathrm{t}+1}$ represents the change of efficiency of the SEZ region from periods $t$ to $t+1$.

Equation (15) can be further converted into the following two aspects by combining Equations (16) and (17):

$$
\begin{aligned}
\mathrm{GM}^{\mathrm{t}, \mathrm{t}+1} & =\mathrm{GTCH}^{\mathrm{t}, \mathrm{t}+1} \times \mathrm{HECH}^{\mathrm{t}, \mathrm{t}+1} \times \mathrm{MECH}^{\mathrm{t}, \mathrm{t}+1} \\
\mathrm{GM}^{\mathrm{t}, \mathrm{t}+1} & =\mathrm{GTCH}^{\mathrm{t}, \mathrm{t}+1} \times \mathrm{RECH}^{\mathrm{t}, \mathrm{t}+1} \times \mathrm{MECH}^{\mathrm{t}, \mathrm{t}+1}
\end{aligned}
$$

In the above decomposition, the dynamic change of SEZs' IEE is composed of three parts from both dimensions. From the dimension of administrative hierarchy, such change includes technological progress efficiency change, hierarchy efficiency change, and MECH. From the dimension of regional location, this change includes technological progress efficiency change, $\mathrm{RECH}$, and MECH.

\subsection{Data Collection and Processing}

Seventy-three SEZs are present in Guizhou. We analyzed the leading industries of 73 SEZs and found that most leading industries in 70 SEZs are traditional manufacturing industries with little difference in production pattern, and the main energy used in 70 SEZs is electricity. The leading industries of another three SEZs are brewing or supporting industries of brewing and service sector. The DEA method requires that all DMUs should be similar; thus, if some DMUs have greater heterogeneity, then the calculated results will be biased. In view of this, we selected 70 SEZs as the research objects (Table 1).

Based on the data availability, this study chose capital stock (K), labor (L), and industrial electricity consumption (e) as input factors and industrial added value as the output factor. All the data were obtained through the comprehensive performance evaluation survey of G-SEZs from year 2016 to 2019.

(1) Labor and industrial electricity consumption. The labor data adopt the annual end-ofterm employment number of SEZs. Industrial electricity consumption is expressed by the electricity consumption of all industrial enterprises within SEZs. 
(2) Industrial added value. Given that the annual SEZ industrial added value during 2016-2019 is the nominal value, we use Guizhou Producer Price Indices for Industrial Products by Category (PPI) to offset and adjust the annual industrial added value on the basis of 2016 .

(3) Capital stock. Only the new fixed assets investment of SEZs every year is used because no direct capital stock index is available in the survey data. We adopt the perpetual inventory method to estimate the actual capital stock of SEZs from 2016 to 2019. The calculation formula is as follows:

$$
K_{i \mathrm{t}}=K_{i, \mathrm{t}-1}(1-\delta)+\frac{I_{\mathrm{t}}}{\mathrm{P}_{\mathrm{t}}}
$$

where $K_{\mathrm{t}}$ and $K_{\mathrm{t}+1}$ represent the capital stock of SEZ $i$ in $\mathrm{t}$ year and $\mathrm{t}-1$ year, respectively; It is the new fixed asset investment of SEZ $i$ in t year, and $P_{t}$ is the price index in $t$ year. We use the fixed asset investment price index of Guizhou Province to offset the new fixed asset investment of each SEZ in the current period. $\delta$ is the capital depreciation rate. In the research methods of Shan [48] and Fan et al. [49], $\delta$ is defined as $10.96 \%$.

Table 1. Descriptive statistics of the input and output variables.

\begin{tabular}{cccccc}
\hline Variables & obs & Mean & Std. Dev. & Mini & Maxi \\
\hline $\begin{array}{c}\text { Capital stock } \\
\text { (RMB 100 million yuan) }\end{array}$ & 280 & 215.68 & 182.11 & 980.80 & 27.00 \\
$\begin{array}{c}\text { Labor } \\
\text { (one worker) }\end{array}$ & 280 & 18,775 & 31,180 & 220,531 & 380 \\
$\begin{array}{c}\text { Industrial electricity consumption } \\
\quad(100 \text { billion kWh) }\end{array}$ & 280 & 5.62 & 8.38 & 57.28 & 0.05 \\
$\begin{array}{c}\text { Industrial added value } \\
\text { (RMB 100 million yuan) }\end{array}$ & 280 & 26.60 & 31.59 & 238.40 & 0.31 \\
\hline
\end{tabular}

\section{Empirical Results and Discussion}

4.1. Decomposition of IEE in SEZs

4.1.1. From the Dimension of Administrative Hierarchy Heterogeneity

According to Equations (2)-(4), we calculated the IEE, ME, and HE of G-SEZs during 2016-2019 (Table 2). The G-SEZs' IEE has always been stable, which has been above 33\% in the past 4 years. We compared the contribution degree of ME and HE to IEE and found that HE has the largest improvement to IEE in the 4 years. This notion indicates that the heterogeneity of administrative hierarchy plays a leading role in the influence of G-SEZs' IEE.

The horizontal comparison of three administrative hierarchy SEZs indicated that the ranking of SEZs' IEE during 2016-2019 stay the same: P-SEZs > C-SEZs > M-SEZs. This result is consistent with the conclusion of Özkara and Atak [35]: The regions with higher per capita GDP have higher IEE, while those with medium per capita GDP have the lowest industrial IEE. The per capita GDP of P-SEZs is the highest among the three administrative hierarchy SEZs, followed by S-SEZs and C-SEZs; therefore, the IEE ranking presents a similar order. M-SEZs' IEE is lowest; this factor is mainly determined by the development demand of the SZEs. M-SEZ is a priority development area of prefecture-level cities, and the municipal government provides more financial support than the county government. For example, the municipal government provides more electricity subsidy to the settled enterprises than county government. This situation distorts electricity market prices, resulting in excessive energy consumption and reducing energy efficiency [50,51]. M-SEZs' IEE has not been improved with the support of preferential policies. 
Table 2. IEE and its decomposition in the three administrative hierarchy SEZs.

\begin{tabular}{ccccc}
\hline Year & Hierarchy & IEE & ME & HE \\
\hline \multirow{3}{*}{2016} & P-SEZs & 0.4584 & 0.5588 & 0.8203 \\
& M-SEZs & 0.2612 & 0.9491 & 0.2752 \\
& C-SEZs & 0.3832 & 0.4077 & 0.9401 \\
& G-SEZs & 0.3688 & 0.4987 & 0.7395 \\
\hline \multirow{2}{*}{2017} & P-SEZs & 0.5252 & 0.6333 & 0.8293 \\
& M-SEZs & 0.3088 & 0.6648 & 0.4645 \\
& C-SEZs & 0.3422 & 0.3616 & 0.9463 \\
\multirow{2}{*}{2018} & G-SEZs & 0.3482 & 0.3995 & 0.8716 \\
& P-SEZs & 0.4324 & 0.4446 & 0.9725 \\
& M-SEZs & 0.2698 & 0.4860 & 0.5552 \\
& C-SEZs & 0.3339 & 0.3514 & 0.9502 \\
& G-SEZs & 0.3340 & 0.3694 & 0.9042 \\
\hline & P-SEZs & 0.5191 & 0.5323 & 0.9752 \\
& M-SEZs & 0.2113 & 0.3737 & 0.5655 \\
& C-SEZs & 0.3420 & 0.3537 & 0.9668 \\
& G-SEZs & 0.3343 & 0.3641 & 0.9181 \\
\hline
\end{tabular}

The ME of the three administrative hierarchy SEZs shows that P-SEZs and M-SEZs are relatively large, and C-SEZs is the smallest. In terms of HE, the technical level of C-SEZs is closest to the meta-frontier. In the past 4 years, the mean value of $\mathrm{HE}$ has reached more than 0.95. During 2016-2018, C-SEZs' HE is the largest among the three administrative hierarchy SEZs. Meanwhile, P-SEZs' HE was close to C-SEZs' HE in 4 years; it surpassed C-SEZs' HE and was closest to the meta-frontier in 2019. Each year, M-SEZs' HE is the smallest of the three administrative hierarchy SEZs and the furthest from the meta-frontier.

The above analysis indicates that the IEE, ME, and HE of the three administrative hierarchy SEZs are greatly different, which is mainly caused by the heterogeneity of administrative hierarchy. Different administrative hierarchies have diverse ability to allocate and attract resources and set permissions [17], which leads to the great differences in IEE, HE, and ME of enterprises in various administrative hierarchy SEZs.

\subsubsection{From the Dimension of Regional Location Heterogeneity}

We calculated the IEE, ME, and RE of SEZs in all regions of Guizhou from 2016 to 2019 by using Equations (7)-(9). We find that RE is always smaller than ME in the 4 years, and IEE is mainly contributed by ME (Table 3).

The Special Economic Zones' IEE in Bijie, Liupanshui, and Qiandongnan is relatively high. The three regions are important resource-rich areas in South China; thus, their SEZs' IEE ranked at the top in the past 4 years, and ME and RE also ranked relatively high, indicating no "resource curse" effect of energy endowment on SEZs' IEE in the three regions. This output is inconsistent with the research conclusions of Sheng, and Zhou and Fang $[52,53]$. The main reasons are as follows. First, the research object of this work is total factor IEE, while the research object of the above scholars is total factor energy efficiency, which has certain differences. Second, the layout of power source points and the structure of power grid are more reasonable in the three regions, which provides efficient, convenient, and stable power for the development of SEZs and greatly improves the IEE. Third, the three regions are promoting the construction of modern industrial agglomeration, and industrial agglomeration can improve energy efficiency in the initial period [54,55].

The IEE ranking of QN-SEZs is relatively outstanding, and it surpassed Bijie to become the first one in 2019. This region actively guides SEZs to develop such industries as ecological utilization, high recycling efficiency, low carbon, and clean. Therefore, the IEE has a great advantage compared with other regions. Qiannan has regional advantage of being adjacent to Guiyang (Guizhou capital). In recent years, Guiyang is in short supply 
of land indicators for industrial development. Many high-tech industries and enterprises gather in nearby Qiannan, which promotes the improvement of SEZs' IEE in Qiannan.

The IEE ranking of ZY-SEZs and QDN-SEZs is basically at the bottom from 2016 to 2019, which may be due to two reasons: First, low IEE is closely related to poverty alleviation. Zunyi and Qiandongnan are the areas with the deepest poverty level in Guizhou. The Special Economic Zones in the two regions pursue excessive economic development speed to achieve poverty alleviation on schedule, which reduces the quality of economic development. Second, many SEZs are in the two regions (13 in Zunyi and 10 in Qiandongnan). Low-level repetitive industrial construction occurs, resulting in lower IEE compared with other regions.

Table 3. IEE and its decomposition in the nine regional SEZs.

\begin{tabular}{|c|c|c|c|c|c|c|c|}
\hline Year & Region & IEE & Ranking & ME & Ranking & RE & Ranking \\
\hline \multirow{10}{*}{2016} & Bijie & 0.7311 & 1 & 0.8831 & 2 & 0.8279 & 3 \\
\hline & Guiyang & 0.5991 & 2 & 0.6471 & 5 & 0.9257 & 1 \\
\hline & Qiannan & 0.4417 & 3 & 0.8027 & 3 & 0.5503 & 6 \\
\hline & Liupanshui & 0.3826 & 4 & 0.5949 & 6 & 0.6432 & 5 \\
\hline & Qianxinan & 0.3419 & 5 & 0.4276 & 8 & 0.7996 & 4 \\
\hline & Tongren & 0.3109 & 6 & 0.6937 & 4 & 0.4483 & 8 \\
\hline & Anshun & 0.2681 & 7 & 0.3046 & 9 & 0.8800 & 2 \\
\hline & Qiandongnan & 0.2384 & 8 & 0.4933 & 7 & 0.4832 & 7 \\
\hline & Zunyi & 0.2039 & 9 & 0.9133 & 1 & 0.2232 & 9 \\
\hline & Guizhou & 0.3688 & - & 0.6738 & - & 0.5474 & - \\
\hline \multirow{10}{*}{2017} & Bijie & 0.7760 & 1 & 0.9064 & 2 & 0.8562 & 3 \\
\hline & Qiannan & 0.4745 & 2 & 0.6641 & 3 & 0.7146 & 5 \\
\hline & Qianxinan & 0.4483 & 3 & 0.4935 & 6 & 0.9084 & 1 \\
\hline & Liupanshui & 0.3828 & 4 & 0.5995 & 5 & 0.6385 & 6 \\
\hline & Guiyang & 0.3756 & 5 & 0.6003 & 4 & 0.6257 & 7 \\
\hline & Tongren & 0.3084 & 6 & 0.3653 & 8 & 0.8442 & 4 \\
\hline & Anshun & 0.3020 & 7 & 0.3514 & 9 & 0.8594 & 2 \\
\hline & Zunyi & 0.2179 & 8 & 0.9149 & 1 & 0.2382 & 9 \\
\hline & Qiandongnan & 0.1641 & 9 & 0.4113 & 7 & 0.3991 & 8 \\
\hline & Guizhou & 0.3482 & - & 0.6319 & - & 0.5510 & - \\
\hline \multirow{10}{*}{2018} & Bijie & 0.5956 & 1 & 0.7824 & 2 & 0.7613 & 3 \\
\hline & Qiannan & 0.5594 & 2 & 0.6543 & 3 & 0.8550 & 1 \\
\hline & Qianxinan & 0.4281 & 3 & 0.5013 & 6 & 0.8540 & 2 \\
\hline & Liupanshui & 0.4073 & 4 & 0.5756 & 4 & 0.7076 & 4 \\
\hline & Guiyang & 0.3557 & 5 & 0.5059 & 5 & 0.7031 & 5 \\
\hline & Anshun & 0.2962 & 6 & 0.4428 & 8 & 0.6690 & 7 \\
\hline & Tongren & 0.2768 & 7 & 0.4034 & 9 & 0.6862 & 6 \\
\hline & Qiandongnan & 0.2299 & 8 & 0.4703 & 7 & 0.4889 & 8 \\
\hline & Zunyi & 0.1507 & 9 & 0.9241 & 1 & 0.1631 & 9 \\
\hline & Guizhou & 0.3340 & - & 0.6178 & - & 0.5406 & - \\
\hline \multirow{10}{*}{2019} & Qiannan & 0.6258 & 1 & 0.9337 & 1 & 0.6703 & 5 \\
\hline & Bijie & 0.5089 & 2 & 0.9224 & 3 & 0.5517 & 7 \\
\hline & Qianxinan & 0.4073 & 3 & 0.5468 & 5 & 0.7449 & 4 \\
\hline & Guiyang & 0.3831 & 4 & 0.4951 & 6 & 0.7738 & 3 \\
\hline & Liupanshui & 0.3444 & 5 & 0.7864 & 4 & 0.4380 & 8 \\
\hline & Tongren & 0.2799 & 6 & 0.3537 & 8 & 0.7912 & 2 \\
\hline & Qiandongnan & 0.2791 & 7 & 0.3325 & 9 & 0.8392 & 1 \\
\hline & Anshun & 0.2665 & 8 & 0.4294 & 7 & 0.6207 & 6 \\
\hline & Zunyi & 0.1758 & 9 & 0.9277 & 2 & 0.1895 & 9 \\
\hline & Guizhou & 0.3343 & - & 0.6653 & - & 0.5024 & - \\
\hline
\end{tabular}

\subsection{Decomposition of the Changes in IEE in SEZS}

\subsubsection{From the Dimension of Administrative Hierarchy Heterogeneity}

We estimate and decompose the dynamic changes of the three administrative hierarchy SEZs' IEE from 2016 to 2019 according to Equations (15) and (18) (Table 4). In 2016-2017 and 2017-2018, the GM values of G-SEZs were 0.7477 and 0.6581 , and the GTCH values were 0.7919 and 0.6861 , respectively, all of which were less than 1 (Table 4). This finding shows that G-SEZs' IEE is declining, and technology is degrading. The TECH is decomposed into two parts: HE and ME. During the period of 2016-2018, HE was greater than 1, 
indicating that the gap between the SEZ technological level at all hierarchies and the optimal technological level was narrowing with the technological decline. Meanwhile, ME is less than 1; however, the decline is less dramatic. We calculate TECH in 2016-2017 and 2017-2018 according to TECH $=\mathrm{HE} \times \mathrm{ME}$, which are 0.9441 and 0.9592 , respectively. The technological utilization efficiency of G-SEZs is continuously declining during 2016-2018.

Table 4. The dynamic change of three administrative hierarchy SEZs' IEE.

\begin{tabular}{|c|c|c|c|c|c|}
\hline \multirow{2}{*}{ Hierarchy } & \multirow{2}{*}{ Year } & \multirow{2}{*}{ GTCH } & \multicolumn{2}{|c|}{ TECH } & \multirow{2}{*}{ GM } \\
\hline & & & $\mathrm{HE}$ & ME & \\
\hline \multirow{3}{*}{ G-SEZs } & 2016-2017 & 0.7919 & 1.1786 & 0.8011 & 0.7477 \\
\hline & 2017-2018 & 0.6861 & 1.0375 & 0.9245 & 0.6581 \\
\hline & 2018-2019 & 1.0672 & 1.0153 & 0.9857 & 1.0680 \\
\hline \multirow{3}{*}{ P-SEZs } & 2016-2017 & 1.0742 & \multicolumn{2}{|c|}{1.1333} & 1.2173 \\
\hline & 2017-2018 & 0.9974 & \multicolumn{2}{|c|}{0.7020} & 0.7002 \\
\hline & 2018-2019 & 0.9790 & \multicolumn{2}{|c|}{1.1973} & 1.1721 \\
\hline \multirow{3}{*}{ M-SEZs } & $2016-2017$ & 0.9575 & \multicolumn{2}{|c|}{0.7005} & 0.6707 \\
\hline & 2017-2018 & 0.8226 & \multicolumn{2}{|c|}{0.7311} & 0.6014 \\
\hline & 2018-2019 & 0.5823 & \multicolumn{2}{|c|}{0.7688} & 0.4476 \\
\hline \multirow{3}{*}{ C-SEZs } & $2016-2017$ & 0.8390 & \multicolumn{2}{|c|}{0.8870} & 0.7442 \\
\hline & 2017-2018 & 0.7297 & \multicolumn{2}{|c|}{0.9718} & 0.7092 \\
\hline & 2018-2019 & 1.1051 & \multicolumn{2}{|c|}{1.0066} & 1.1123 \\
\hline
\end{tabular}

The GM, TECH, and GTCH of G-SEZs have been declining from 2016 to 2018, which is influenced by China and Guizhou government economic development policies in the past three years. First, in response to the central government's call to cut overcapacity, Guizhou shut down a number of coal, coal power, and other backward energy enterprises. However, the high-quality capacity has not been added in a timely and effective manner. Second, Guizhou has launched the "Thousands of Enterprises Transformation" project in 2016. During the transformation, the project tends to pursue the enterprise scale to be bigger and for output to increase, and it does not make much effort to improve the energy utilization technology. Third, the task of poverty alleviation undertaken by SEZs is increasing year by year. SEZs greatly pursue the speed of economic development to solve the employment of poor people and achieve poverty alleviation and prosperity, which results in the decline of enterprise production quality and has a negative impact on SEZs' IEE. Fourth, China has implemented measures to prevent and defuse major risks in the financial sector since 2017, leading to prominent problems of financing difficulties and high financing costs for enterprises. Enterprises in SEZs have relaxed their efforts in energy conservation and emission reduction to reduce production costs and increase profit margins.

In 2019, the GM of G-SEZs showed a turning point, reaching 1.0680. The GTCH and TECH were 1.0672 and 1.0008 , respectively. In the TECH decomposition, HE is 1.0153, and $\mathrm{ME}$ is 0.9857 . This notion indicates that the gap between the technological frontier of the three administrative hierarchy SEZs and the optimal technological frontier of G-SEZs continues to narrow. However, the management level is still declining compared with the previous year, which means that the improvement of TECH is caused by the increase of HE. The changes in GM, GTCH, and TECH are attributed to the following reasons. First, Guizhou implemented central government's policy of reducing taxes and fees in 2019, and the value-added tax rate of the manufacturing industry was reduced from $16 \%$ to $13 \%$. The reduction of tax can stimulate the innovation ability of enterprises and increase the $R \& D$ investment and the number of patents granted by enterprises [56,57], thereby effectively promoting the improvement of IEE. Second, Guizhou carried out the integration of big data, and traditional industries greatly improve their green level in 2019 [58].

The GM, GTCH, and TECH of three administrative hierarchy SEZs do not maintain the same trend as G-SEZs from 2016 to 2019. Only C-SEZs and G-SEZs have the same 
trend mainly because the former account for a large number and heavily influenced by the overall economic policy of Guizhou. Guizhou's overcapacity reduction policy did not cause a negative impact on P-SEZs' IEE compared with other two administrative hierarchy SEZs because P-SEZs had less excess capacity, and some measures were not applicable to them. The GM, GTCH, and TECH of M-SEZs are all less than 1 from 2016 to 2019, indicating that IEE, technological progress rate, and technological utilization rate are declining year by year, and the decline rate is increasing. This situation is different from the changes of G-SEZs, relating to the preferential electricity subsidy policy of M-SEZs and excessive pursuit of economic development speed.

\subsubsection{From the Dimension of Regional Location Heterogeneity}

We calculated and decomposed the dynamic changes of SEZs' IEE in the nine regions of Guizhou during 2016-2019 according to Equations (15), (17) and (19) (Table 5). From a regional location perspective, the TECH of G-SEZs is divided into RE and ME. In 2016, RE is 1.0067 (greater than 1), indicating that the technical level of each region is progressing. During 2017-2018 and 2018-2019, REs were 0.9810 and 0.9295, respectively (both less than 1 ), showing that the technical level of each region was differentiated, and the distance from optimal meta-frontier was enlarged. The dynamic change values of ME were less than 1 in 2016-2017 and 2017-2018, which were 0.9379 and 0.9778, respectively, indicating that the management level decreased year by year in the 3 years. However, ME changed to 1.0768 in 2019, which was greater than 1, indicating that management level was improved. The dynamic changes of GM of the nine regional SEZs are similar to those of the three administrative hierarchy SEZs from 2016 to 2019. Not all regional SEZs and G-SEZs maintain the same trend. The GM of GY-SEZs, ZY-SEZs, TR-SEZs, QDN-SEZs, QN-SEZs, and G-SEZs have the same variation trend. In other regions, SEZs' GM varies.

The GM, GTCH, and TECH of Guiyang, the capital city of Guizhou, were all less than 1 from 2016 to 2017. This result is because Guiyang relocated traditional industries with high energy consumption from urban areas to SEZs in 2017, thus reducing the technical level, technological utilization rate, and IEE of enterprises in GY-SEZs. From 2017 to 2018, the GM and TECH of GY-SEZs were less than 1; however, GTCH was greater than 1 (1.0024). In this year, Guiyang strictly implemented the integration of big data and manufacturing development, and key industrial enterprises began to carry out digital R\&D and design, which greatly improved the manufacturing technological level in GY-SEZs. However, the technological utilization rate was low because the management level failed to keep up with it, which diminished the GM. From 2018 to 2019, Guiyang accelerated the agglomeration of middle and high-end manufacturing industry. The elimination of backward production capacity reached 990,000 tons, which promoted the improvement of IEE. The GM reached 1.2422, and technological progress improved again, with GTCH at 1.2692. However, the $\mathrm{TECH}$ is still below one, although the rate of decline is slower.

Zunyi, Tongren, and Qiandongnan are relatively poor areas in Guizhou. Many lowlevel and homogeneous manufacturing enterprises can be found in SEZs, with serious excess capacity. The GM of SEZs in the three regions is less than 1 during 2016-2017 and 2017-2018 and greater than 1 during 2018-2019. With the implementation of the Guizhou overcapacity-cutting policy, the three regions sought to make the industries bigger and stronger from 2016 to 2018, which led to many small enterprises with relatively good technical level being included in excess capacity for removal. Accordingly, the technical level of SEZs in the three regions showed a downward trend, and GTCH was less than 1 during 2016-2017 and 2017-2018. The technological utilization efficiency of ZY-SEZs has not declined due to technological degradation, but has been increasing year by year from 2017 to 2019, and the TECH has been greater than 1 for three consecutive years. The TECH of TR-SEZs and QDN-SEZs was less than 1 in 2016-2017 and greater than 1 in 2017-2018. From 2018 to 2019, the GTCH of SEZs in the three regions showed a turning point, promoting the improvement of GM and IEE, which was greatly related to the provincial policy of tax and fee reduction. 
Table 5. The dynamic change of nine regional SEZs' IEE.

\begin{tabular}{|c|c|c|c|c|c|}
\hline \multirow{2}{*}{ Regions } & \multirow{2}{*}{ Year } & \multirow{2}{*}{ GTCH } & \multicolumn{2}{|c|}{ TECH } & \multirow{2}{*}{ GM } \\
\hline & & & RE & ME & \\
\hline \multirow{3}{*}{ G-SEZs } & 2016-2017 & 0.7919 & 1.0067 & 0.9379 & 0.7477 \\
\hline & 2017-2018 & 0.6861 & 0.9810 & 0.9778 & 0.6581 \\
\hline & 2018-2019 & 1.0672 & 0.9295 & 1.0768 & 1.0680 \\
\hline \multirow{3}{*}{ GY-SEZs } & 2016-2017 & 0.4841 & \multicolumn{2}{|c|}{0.9276} & 0.4490 \\
\hline & 2017-2018 & 1.0024 & \multicolumn{2}{|c|}{0.8428} & 0.8448 \\
\hline & 2018-2019 & 1.2692 & \multicolumn{2}{|c|}{0.9787} & 1.2422 \\
\hline \multirow{3}{*}{ ZY-SEZs } & 2016-2017 & 0.7572 & \multicolumn{2}{|c|}{1.0017} & 0.7585 \\
\hline & 2017-2018 & 0.2410 & \multicolumn{2}{|c|}{1.0101} & 0.2434 \\
\hline & 2018-2019 & 2.1312 & \multicolumn{2}{|c|}{1.0039} & 2.1395 \\
\hline \multirow{3}{*}{ LPS-SEZs } & 2016-2017 & 0.7702 & \multicolumn{2}{|c|}{1.0078} & 0.7762 \\
\hline & 2017-2018 & 0.8226 & \multicolumn{2}{|c|}{0.9601} & 0.7898 \\
\hline & 2018-2019 & 0.6823 & \multicolumn{2}{|c|}{1.3662} & 0.9322 \\
\hline \multirow{3}{*}{ AS-SEZs } & 2016-2017 & 0.9289 & \multicolumn{2}{|c|}{1.1535} & 1.0715 \\
\hline & 2017-2018 & 0.6601 & \multicolumn{2}{|c|}{1.2599} & 0.8317 \\
\hline & 2018-2019 & 1.0443 & \multicolumn{2}{|c|}{0.9699} & 1.0128 \\
\hline \multirow{3}{*}{ BJ-SEZs } & 2016-2017 & 0.8236 & \multicolumn{2}{|c|}{1.0264} & 0.8453 \\
\hline & 2017-2018 & 0.6449 & \multicolumn{2}{|c|}{0.8632} & 0.5567 \\
\hline & 2018-2019 & 0.7335 & \multicolumn{2}{|c|}{1.1789} & 0.8647 \\
\hline \multirow{3}{*}{ TR-SEZs } & $2016-2017$ & 0.8173 & \multicolumn{2}{|c|}{0.5267} & 0.4304 \\
\hline & 2017-2018 & 0.6727 & \multicolumn{2}{|c|}{1.1043} & 0.7428 \\
\hline & 2018-2019 & 1.3622 & \multicolumn{2}{|c|}{0.8768} & 1.1944 \\
\hline & 2016-2017 & 0.6802 & & & 0.5672 \\
\hline QDN-SEZs & 2017-2018 & 0.6903 & & & 0.7892 \\
\hline & 2018-2019 & 1.9963 & & & 1.4115 \\
\hline & 2016-2017 & 0.9837 & & & 0.8139 \\
\hline QN-SEZs & 2017-2018 & 0.8536 & & & 0.8410 \\
\hline & 2018-2019 & 0.7881 & & & 1.1246 \\
\hline & 2016-2017 & 1.0836 & & & 1.2504 \\
\hline QXN-SEZs & 2017-2018 & 0.4674 & & & 0.4748 \\
\hline & 2018-2019 & 1.0074 & & & 1.0988 \\
\hline
\end{tabular}

As the energy and resource-rich areas, Bijie, Liupanshui, and Qianxinan, have many energy-related enterprises in SEZs and serious excess capacity. Accordingly, IEE is greatly affected by the overcapacity-cutting policy; however, the degree of impact varies. This situation is due to the variation in the energy resource reserve in the three regions. In the process of overcapacity reduction, Bijie and Liupanshui took a long time, and many small and medium-sized enterprises related to coal withdrew from the market. Nevertheless, many large and medium-sized enterprises were not integrated, resulting in the gradual degradation of the SEZ technological level. Accordingly, the GTCH of the two regions was less than 1 from 2016 to 2019, and the GM was also lowered. Qiandongnan basically realized the removal of energy-related excess capacity in 2016. The technical level, technological utilization efficiency, and IEE of QXN-SEZs have been improved by 2017 due to the improvement of energy efficiency in coal, smelting and other industries, and the GTCH, $\mathrm{TECH}$, and GM are all greater than 1. In 2018, many export-oriented enterprises in QXNSEZs could not update their technical equipment in time because of the influence of China-US trade friction. Although the ME $($ TECH $>1)$ was improved, IEE $(\mathrm{GM}<1)$ was still affected and decreased. In 2019, Guizhou implemented the policies of tax and fee reduction and enterprise integration, which stimulated the vitality of QXN-SEZ enterprises. The GTCH, TECH, and GM were all greater than 1, and IEE was improved. 
In Anshun, a demonstration zone of civil-military integration in Guizhou, aviation manufacturing, general aviation, high-end equipment, and other industries account for a large proportion, which leads to the difference in IEE change between AS-SEZs and G-SEZs. The technological utilization efficiency of AS-SEZs has been significantly improved because Anshun has been promoting civil-military integration from 2016 to 2018. The TECH of 2016-2017 and 2017-2018 is both greater than 1. However, the technical level of AS-SEZs deteriorated in 2016-2017 and 2017-2018 because of the overcapacity-cutting policy, and the GTCH was less than 1. In particular, the GTCH became even smaller due to the China-US trade friction in 2017-2018. In 2018-2019, GTCH is greater than 1 owing to the tax and fee reduction. However, the technological utilization efficiency has slightly decreased due to the increase in the proportion of output value of coal, electric power, non-ferrous metal, and other high-energy consuming enterprises. Nevertheless, the GM is still greater than 1, and IEE has improved.

In QN-SEZs, as the base of phosphorus chemical industry in Guizhou, the proportion of phosphorus chemical industry is large; however, the layout problem of "scattered, chaotic, and small" appears. During capacity reduction, small enterprises related to phosphorus chemical industry have been shut down. However, many large and medium-sized enterprises have not yet been established and operated, reducing the overall technology level of QN-SEZs. The GTCH is all less than 1 from 2016 to 2019. However, Qiannan implemented the measures of manufacturing energy gradient utilization within QN-SEZs in 2019 to build an ecological city, and the technological utilization efficiency was greatly improved. The TECH was 1.4270, which droved GM to 1.1246 and promoted IEE improvement.

\subsection{Decomposition of IEI and IEP in SEZs}

\subsubsection{From the Dimension of Administrative Hierarchy Heterogeneity}

We calculate and decompose the IEI and IEP of the three administrative hierarchy SEZs according to Equations (5) and (6). The results are shown in Figure 4.

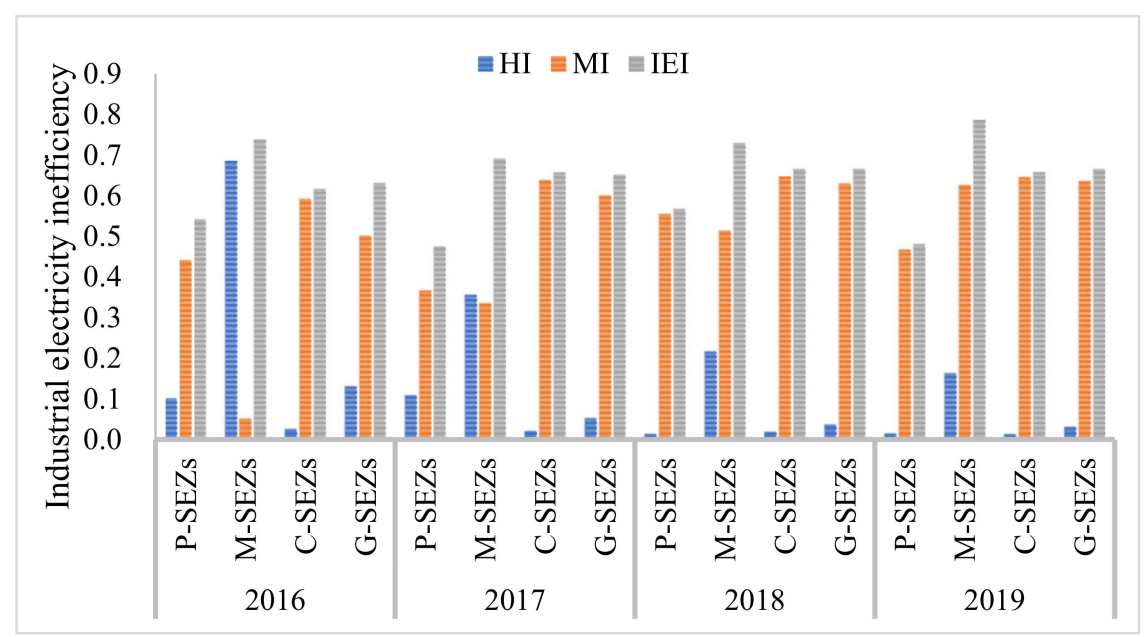

Figure 4. IEI and its decomposition in three hierarchy SEZs.

From the perspective of the whole province, the IEI is above $60 \%$ from 2016 to 2019 and has an increasing trend every year. This notion indicates that more than $60 \%$ of electricity consumption in G-SEZs is wasted, and the waste percentage is increasing. MI accounted for the majority of IEI, with the proportion increasing from $79.42 \%$ to $95.52 \%$ in $2016-2019$. By contrast, HI accounted for a small proportion of IEI, with the proportion decreasing from $20.58 \%$ to $4.48 \%$ in $2016-2019$. The IEI of G-SEZs is mainly caused by MI, and the influence of administrative hierarchy on IEI is weakening. The horizontal comparison of the three administrative hierarchy SEZs shows that M-SEZs' IEI is the largest, followed by C-SEZs' IEI and P-SEZs' IEI from 2016 to 2019. Therefore, SEZ power waste has a significant administrative hierarchy heterogeneity. In terms of the effect of MI and HI on 
IEI, the proportion of MI and HI accounting for IEI in the three administrative hierarchy SEZs during 2016-2017 is not the same as that of G-SEZs. In 2016 and 2017, M-SEZs' MI did not account for the largest proportions of IEI, which were $6.89 \%$ and $48.49 \%$, respectively. Meanwhile, HI accounted for a large proportion. C-SEZs and P-SEZs have the same status as G-SEZs' MI predominates. From 2018 to 2019, the MI performance in the three administrative hierarchy SEZs is the same as that of G-SEZs, and IEI in each administrative hierarchy is mainly caused by MI. This notion shows that power waste is still caused by poor management in the development of SEZs. Although the difference of administrative hierarchies causes power waste to a certain extent, its influence is weak.

According to IEI and its decomposition, we calculated the IEP, MP, and HP (Figure 5). As far as Guizhou is concerned, IEP has been very large from 2016 to 2019, with an annual average of $256.57 \mathrm{kWh}$, and shows an upward trend in 2019, with an increase of $5.10 \mathrm{kWh}$ compared with that in 2018. From the value of MP and HP, MP accounted for a large proportion of IEP, with an increasing trend year by year, and kept above $200 \mathrm{kWh}$ for four consecutive years. This notion is greatly related to the change of proportion of MI in IEI. The value of HP is small and decreases year by year (from $58.22 \mathrm{kWh}$ in 2016 to $10.59 \mathrm{kWh}$ in 2019).

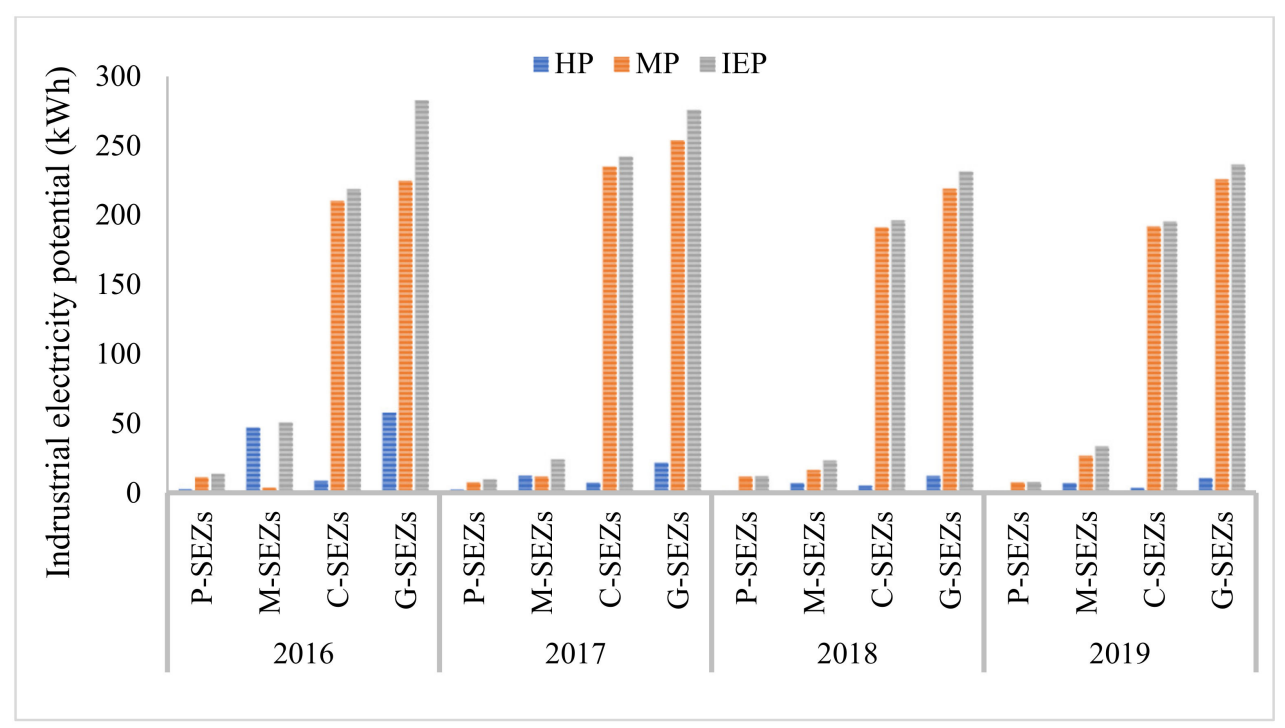

Figure 5. IEP and its decomposition in three hierarchy SEZs.

The horizontal comparison of the three administrative hierarchy SEZs' IEP shows that C-SEZs' IEP is the largest, followed by M-SEZs' IEP and P-SEZs' IEP, which is different from IEI. Although C-SEZs' IEI is less than M-SEZs' IEI, its total electricity-saving potential is greater than that of M-SEZs due to the large number of C-SEZs. This notion further indicates that the key to reducing the power consumption of G-SEZs is to reduce the power consumption of C-SEZs, and only in this way can G-SEZs significantly reduce the power consumption and improve the overall IEE. From the perspective of MP and HP in the three administrative hierarchy SEZs, their performance is not consistent during 2016-2017. The MP of P-SEZs and C-SEZs is much larger than HP, while the MP of M-SEZs is smaller than HP. From 2018 to 2019, the three administrative hierarchy SEZs showed that MP takes up a large part, and HP occupies a small part. Therefore, the energy-saving focus of three administrative hierarchy SEZs is also to improve management.

\subsubsection{From the Dimension of Regional Location Heterogeneity}

According to Equation (11), IEI is decomposed into two parts from the perspective of the region: MI and RI. Figure 6 shows that G-SEZs' MI is always larger than G-SEZs' RI from 2016 to 2019; however, the difference between the two is small. As of 2019, MI is 0.3347 , and RI is 0.3310 , with a difference of 0.0037 , which is almost the same. This 
finding indicates that regional heterogeneity has a growing influence on IEI and becomes an important factor that cannot be ignored to improve IEE. In improving IEE, Guizhou should not only pay attention to the influence of management level but also curb the negative effect caused by regional heterogeneity.

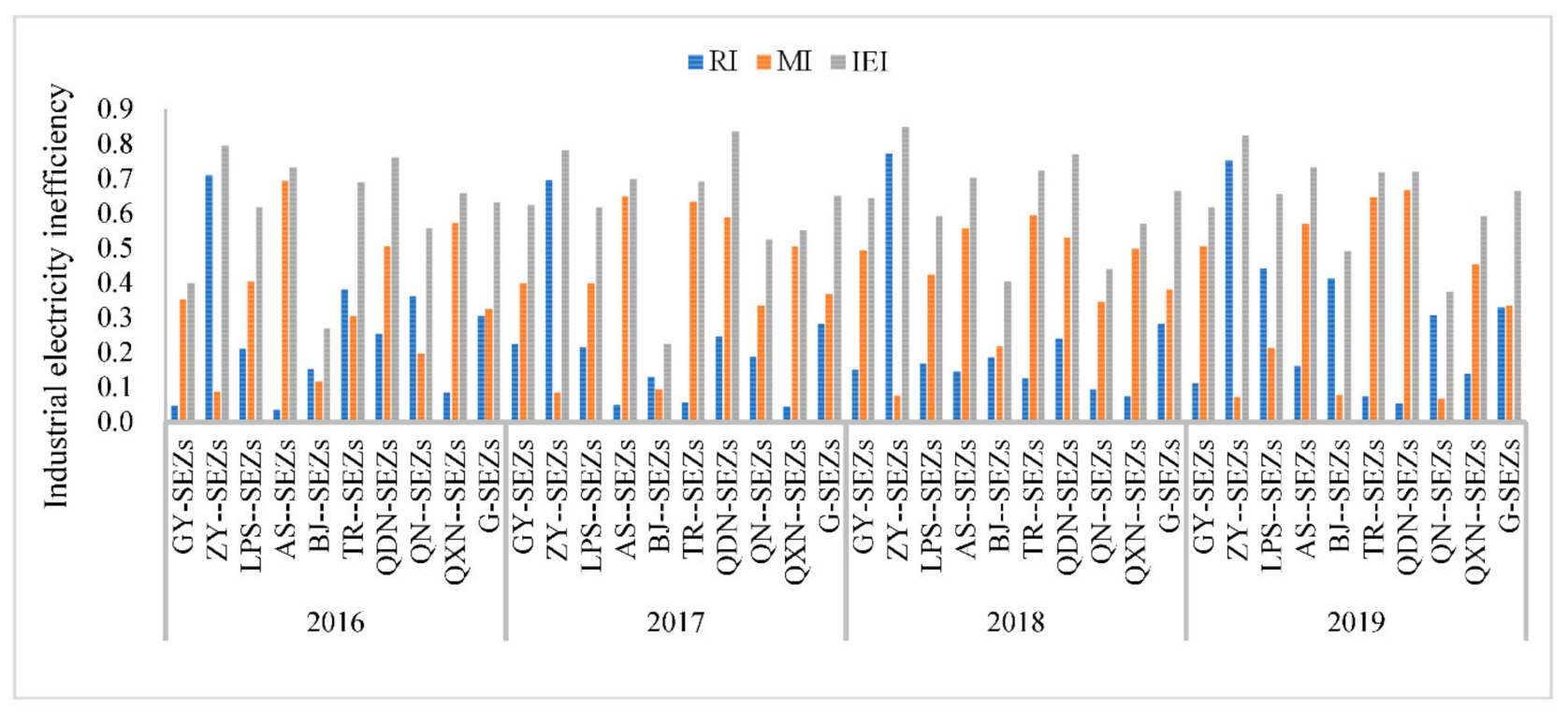

Figure 6. IEI and its decomposition in nine regional SEZs.

The horizontal comparison of nine regional SEZs in Guizhou shows that SEZs' IEI in each region varies from 2016 to 2019 . Nevertheless, the variation implies a certain stable state, that is, the SEZs' IEI in the energy and resource-rich area and Qiannan ecological area is relatively low. In Zunyi and Qiandongnan, SEZs' IEI has been at a high level for 4 years because of the wide range of poverty-stricken areas and the numerous establishment of SEZs. In Guiyang, Tongren, and Anshun, SEZs' IEI has been in the medium level in the past 4 years. The comparison of the proportions of RI and MI in IEI at all regions indicates that the relationship between $\mathrm{RI}$ and $\mathrm{MI}$ is relatively complex. Some regions, such as GY-SEZs, AS-SEZs, QDN-SEZs, and QXN-SEZs, showed RI < MI for 4 consecutive years. In some regions, such as ZY-SEZs, RI > MI was observed for 4 consecutive years. Meanwhile, the RI and MI irregularly changed during the 4 years in other areas, such as TR-SEZs and LPS-SEZs. The different proportions of RI and MI in different regions fully indicate that regional location heterogeneity has a great impact on the degree of power waste in different regions.

According to Equation (15), we decompose IEP into two components: RP and MP (Figure 7). The G-SEZs' IEP appears to be decreasing year by year. However, the total amount of EP is still at a high level, with an annual average of $256.37 \mathrm{kWh}$. As of 2019, the total amount of EP is as high as $236.45 \mathrm{kWh}$. The comparison between MP and RP indicated that G-SEZs' MP has always been larger than G-SEZs' RP in the past 4 years; however, the volume of both are relatively large, which indicates that G-SEZs have a lot of room for improvement in terms of management level and regional coordination.

The performance of SEZs' IEP in each region is different from that of IEI because the number of SEZs in each region varies, leading to the change of SEZs' IEP. ZY-SEZs' IEP is always the largest, with an annual mean value of $72.27 \mathrm{kWh}$, and RP accounts for the majority, while MP accounts for a small proportion. As the provincial capital, GY-SEZs' IEP ranked second in the regional ranking, with $33.71 \mathrm{kWh}$ in 2019, the majority of which is MP. In the energy and resource-rich area, not all SEZs of the three areas have the lowest IEP. The IEPs of QXN-SEZs and LPS-SEZs are at a high level, which are 26.81 and $19.82 \mathrm{kWh}$, respectively, in 2019. However, BJ-SEZs' IEP has been at a low level for 4 years. The change of SEZs' IEP in other regions is basically the same as that of SEZs' IEI in 4 years. 


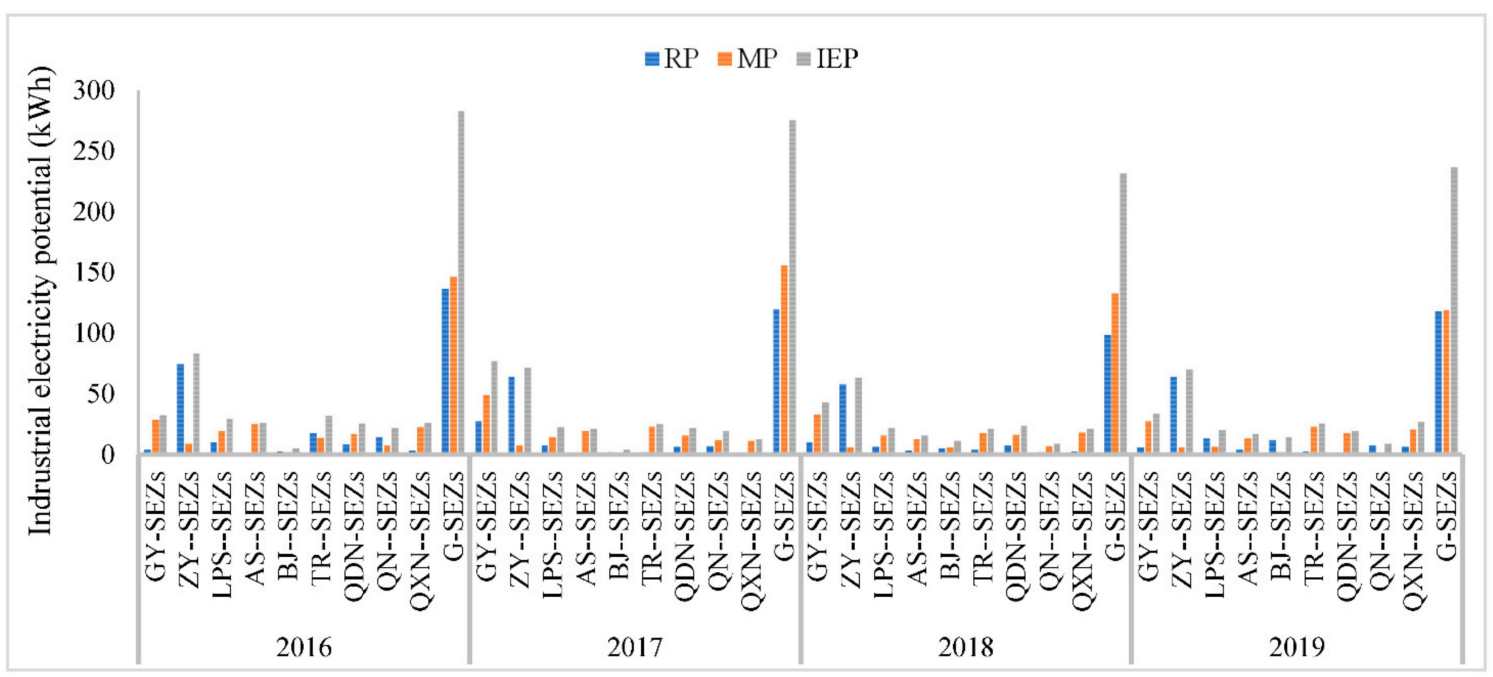

Figure 7. IEP and its decomposition in nine regional SEZs.

\section{Conclusions and Policy Implications}

In this study, a two-dimension and two-level meta-frontier DEA model is adopted to measure and decompose SEZs' IEE from the dual heterogeneity of administrative hierarchy and regional location: $\mathrm{HE}$ and $\mathrm{ME}$ and RE and ME. On this basis, we calculate the IEP of the dual heterogeneity: HP and MP and RP and MP. We introduced GM to decompose and analyze the dynamic change of G-SEZs, three administrative hierarchy SEZs, and nine regional SEZs. The limitations of this study are that the SEZs are not an administrative division in China, so it is difficult to obtain historical data. Since we conducted the research based on 4-year field survey data, the time cycle was short, and some potential conclusions could not be fully explored. The main results are as follows to study the influence of administrative hierarchy and regional location on the change of SEZs' IEE performance. Among them, the first two results are general findings, and the last three results are local findings, with the local characteristics of Guizhou.

1. Due to the heterogeneity of administrative hierarchies, SEZs' IEE was significantly different among various administrative hierarchies. This situation is not that the higher the administrative hierarchy of SEZs, the more efficient the IEE is. The ranking of IEE among three administrative hierarchy SEZs was: P-SEZs' IEE > C-SEZs' IEE > M-SEZs' IEE.

2. SEZs' IEE varies among regions because of the regional differences in resource endowment, poor population distribution, and economic development level. In summary, SEZs' IEE is relatively high in areas with rich energy and resources and good ecological environment. SEZs' IEE is lower in areas with deeper poverty.

3. From 2016 to 2018, the IEE, GTCH, and TECH of G-SEZs have been declining under the influence of China's macro policies, such as reducing overcapacity, preventing, and defusing major risks in the financial sector and local factors, such as the "Thousands of Enterprises Transformation" project in Guizhou. In 2019, SEZs' IEE increased because of China's tax and fee reduction and Guizhou's "Thousands of Enterprises Integration" project.

4. From 2016 to 2019, the GM, GTCH, and TECH of the three administrative hierarchy SEZs did not all keep the same trend with G-SEZs. Only C-SEZs and G-SEZs kept the same trend. The dynamic change of SEZs' IEE in nine regions was more complex. The Special Economic Zones' GM only in five regions had the same variation trend as G-SEZs' GM, and the GM of the other four regions had no certain rule in dynamic change.

5. From the perspective of electricity-saving potential, the overall IEP of G-SEZs appears to be declining year by year. However, the total IEP is still at a high level. The 
two-dimension decomposition results show a stable state: MP $>\mathrm{HP}$ and MP $>$ RP. Nevertheless, the former has a large gap, while the latter has a small gap. Among the three administrative hierarchy SEZs, C-SEZs have the highest IEP, followed by M-SEZs and P-SEZs. In comparison with the decomposition results of IEP, MP > HP in the three administrative hierarchy SEZs, and a large gap exists between them. Among the nine regional SEZs, the IEP of ZY-SEZs and GY-SEZs located in areas with large economic volume are relatively large. Meanwhile, the IEP of BJ-SEZs (development and poverty alleviation and ecological construction pilot zone) and QN-SEZs (ecological city) are relatively small.

On the basis of the above results, we proposed the following policy suggestions for the government to better improve the IEE of G-SEZs. First, the provincial government should increase provincial financial funds to attract outstanding technical talents and improve the ME of energy use in C-SEZs. Second, the municipal government should increase the R\&D investment and equipment update in energy technology and improve the energy technological level of M-SEZs. Third, based on the regional resource endowment, the local government should utilize comparative advantages to promote the transformation and upgrading of traditional industries and increase the proportion of emerging industries. Fourth, the provincial government should optimize the industrial layout of SEZs in povertystricken areas to reduce low-level repetitive construction and energy waste. Fifth, the energy efficiency of a region is affected by industrial agglomeration [59-61], and so are the SEZs. The local governments should guide relevant industries to gather in the region to produce agglomeration effect based on local resource advantages, which will promote the agglomeration effect and ultimately reduce the overall energy consumption cost and improve the energy consumption efficiency. Sixth, the government should take precise measures to prevent the elimination of technology-advanced small and medium-sized enterprises in the process of transforming and reducing overcapacity in the traditional manufacturing industry. The government should avoid only focusing on the improvement of production technology and ignoring the improvement of energy technology while pursuing rapid economic growth. Seventh, in terms of IEP, Guizhou should focus on C-SEZs and SEZs with large regional economic volume (such as GY-SEZs and ZY-SEZs) and strive to improve the management level of the two types of SEZs in the future.

Author Contributions: Conceptualization, Formal analysis, Methodology, Writing-original draft, J.Y.; Validation, Writing - Reviewing and Editing, X.C.; Software, Investigation, Methodology, Supervision, J.C.; All authors have read and agreed to the published version of the manuscript.

Funding: We express our gratitude for the financial support received from the Post-funded Project of Innovation Program of Guizhou Academy of Social Science (CXHQ 2104).

Institutional Review Board Statement: Not applicable.

Informed Consent Statement: Not applicable.

Data Availability Statement: Not applicable.

Conflicts of Interest: The authors declare no conflict of interest.

\section{References}

1. Chen, J.; Wang, Y.; Shi, Q.; Peng, X.; Zheng, J. An international comparison analysis of $\mathrm{CO}_{2}$ emissions in the construction industry. Sustain. Dev. 2021, 4, 754-767. [CrossRef]

2. Xu, P.; Xiaoma, T.; Hao, Z.; Jindao, C.; Kuishuang, F. $\mathrm{CO}_{2}$ emissions from the electricity sector during China's economic transition: From the production to the consumption perspective. Sustain. Prod. Consum. 2021, 27, 1010-1020.

3. GBS. Guizhou Statistical Yearbook; China Statistics Press: Beijing, China, 2019.

4. Zhu, L.; Philippe, C.; Steve, D. Carbon Monitor. Available online: https://arxiv.org/abs/2004.13614 (accessed on 1 September 2020).

5. He, Y.; Fu, F.; Liao, N. Exploring the path of carbon emissions reduction in China's industrial sector through energy efficiency enhancement induced by R\&D investment. Energy 2021, 225, 120208. [CrossRef]

6. Ouyang, X.; Chen, J.; Du, K. Energy efficiency performance of the industrial sector: From the perspective of technological gap in different regions in China. Energy 2021, 214, 118865. [CrossRef] 
7. Ji, J.; Wang, S.; Ma, Y.; Lu, C.; Liang, T.; Zhang, R. Pollutant emission reduction of energy efficiency enhancement and energy cascade utilization in an energy-intensive industrial park in China. Env. Sci. Pollut Res. Int. 2020, 27, 35017-35030. [CrossRef]

8. Zhang, L.; Yuan, Z.; Bi, J.; Zhang, B.; Liu, B. Eco-industrial parks: National pilot practices in China. J. Clean. Prod. 2010, 18, 504-509. [CrossRef]

9. NDRC. China Development Zone Audit Notice Catalogue. Available online: https://www.ndrc.gov.cn/fggz/lywzjw/zcfg/2018 03/t20180302_1047056.html (accessed on 1 September 2020).

10. MOFCOM. China Commerce Yearbook; Ministry of Commerce of the People's Republic of China: Beijing, China, 2018.

11. Guo, Y.; Tian, J.; Zang, N.; Gao, Y.; Chen, L. The role of industrial parks in mitigating greenhouse gas emissions from China. Environ. Sci. Technol. 2018, 52, 7754-7762. [CrossRef] [PubMed]

12. Cheng, Z.; Liu, J.; Li, L.; Gu, X. Research on meta-frontier total-factor energy efficiency and its spatial convergence in Chinese provinces. Energy Econ. 2020, 86. [CrossRef]

13. Du, K.; Lu, H.; Yu, K. Sources of the potential CO2 emission reduction in China: A nonparametric metafrontier approach. Appl. Energy 2014, 115, 491-501. [CrossRef]

14. Feng, C.; Wang, M.; Zhang, Y.; Liu, G.-C. Decomposition of energy efficiency and energy-saving potential in China: A threehierarchy meta-frontier approach. J. Clean. Prod. 2018, 176, 1054-1064. [CrossRef]

15. Manderson, E.J.; Kneller, R. Energy endowments and the location of manufacturing firms. J. Environ. Econ. Manag. 2020, 101. [CrossRef]

16. Liu, L.; Zhang, B.; Bi, J.; Wei, Q.; He, P. The greenhouse gas mitigation of industrial parks in China: A case study of Suzhou Industrial Park. Energy Policy 2012, 46, 301-307. [CrossRef]

17. Wang, Z.; Wang, Y.; Wang, Y.; Chen, J. Urban administrative rank and economic growth: From the perspective of development zone. Macroeconomics 2017, 11, 115-127.

18. Xie, X.; Tang, X.; Fu, Y. Do cities with high administrative level help enterprises to improve productivity? J. World Econ. 2017, 40, 120-144.

19. Kazak, J.K.; Kamińska, J.A.; Madej, R.; Bochenkiewicz, M. Where renewable energy sources funds are invested? Spatial analysis of energy production potential and public support. Energies 2020, 13, 5551. [CrossRef]

20. Busso, M.; Gregory, J.; Kline, P. Assessing the incidence and efficiency of a prominent place based policy. Am. Econ. Rev. 2013, 103, 897-947. [CrossRef]

21. Zheng, G.; Barbieri, E.; Di Tommaso, M.R.; Zhang, L. Development zones and local economic growth: Zooming in on the Chinese case. China Econ. Rev. 2016, 38, 238-249. [CrossRef]

22. Qiangmin, X.I.; Ruidong, S.U.N.; Lin, M.E.I. The impact of special economic zones on producer services productivity: Evidence from China. China Econ. Rev. 2021, 65, 101558. [CrossRef]

23. Alkon, M. Do special economic zones induce developmental spillovers? Evidence from India's states. World Dev. 2018, 107, 396-409. [CrossRef]

24. Yan, G.; Sun, Q.; Chen, C.; Zhong, H.; Ren, J. Research on the evaluation indicator system for innovation level in Chinese national hi-tech industrial development zone. China Soft Sci. 2008, 4, 141-148.

25. Wang, L.; Pan, J.; Guo, R.; Liu, H. Evaluation on operational efficiency of national-level high-tech industrial development zones based on DEA method. J. Ind. Technol. Econ. 2019, 38, 50-57.

26. Zhang, X.; Zha, D.; Kong, F. Evaluation on input efficiency of production factors in the national economic and technological development zone of Jiangxi province: Empirical analysis based on malmquist index model and dynamic panel model. Sci. Technol. Manag. Res. 2018, 38, 69-76.

27. Liddle, B. Electricity intensity convergence in IEA/OECD countries: Aggregate and sectoral analysis. Energy Policy 2009, 37, 1470-1478. [CrossRef]

28. Inglesi-Lotz, R.; Blignaut, J.N. Electricity intensities of the OECD and South Africa: A comparison. Renew. Sustain. Energy Rev. 2012, 16, 4491-4499. [CrossRef]

29. Inglesi-Lotz, R.; Blignaut, J.N. Improving the electricity efficiency in South Africa through a benchmark-and-trade system. Renew. Sustain. Energy Rev. 2014, 30, 833-840. [CrossRef]

30. Davies, R.B. The impact of special economic zones on electricity intensity of firms. Energy J. 2018, 39. [CrossRef]

31. Lin, B.; Zhu, J. Chinese electricity demand and electricity consumption efficiency: Do the structural changes matter? Appl. Energy 2020, 262, 114505. [CrossRef]

32. Broadstock, D.C.; Li, J.; Zhang, D. Efficiency snakes and energy ladders: A (meta-)frontier demand analysis of electricity consumption efficiency in Chinese households. Energy Policy 2016, 91, 383-396. [CrossRef]

33. Andor, M.A.; Bernstein, D.H.; Sommer, S. Determining the efficiency of residential electricity consumption. Empir. Econ. 2021, 60, 2897-2923. [CrossRef]

34. Twerefou, D.K.; Abeney, J.O. Efficiency of household electricity consumption in Ghana. Energy Policy 2020, 144, 111661. [CrossRef]

35. Özkara, Y.; Atak, M. Regional total-factor energy efficiency and electricity saving potential of manufacturing industry in Turkey. Energy 2015, 93, 495-510. [CrossRef]

36. He, Y.; Guang, F.; Wang, M. The efficiency of electricity-use of China and its influencing factors. Energy 2018, 163, 258-269. [CrossRef] 
37. O'Donnell, C.J.; Rao, D.S.P.; Battese, G.E. Metafrontier frameworks for the study of firm-level efficiencies and technology ratios. Empir. Econ. 2007, 34, 231-255. [CrossRef]

38. Wang, H.; Lei, Y.; Wang, H.; Liu, M.; Yang, J.; Bi, J. Carbon reduction potentials of China's industrial parks: A case study of Suzhou Industry Park. Energy 2013, 55, 668-675. [CrossRef]

39. Chen, Y.; Wang, M.; Feng, C.; Zhou, H.; Wang, K. Total factor energy efficiency in Chinese manufacturing industry under industry and regional heterogeneities. Resour. Conserv. Recycl. 2021, 168, 105255. [CrossRef]

40. Charnes, A.; Cooper, W.W.; Rhodes, E. Measuring the efficiency of decision making units. Eur. J. Oper. Res. 1978, 2, 429-444. [CrossRef]

41. Hu, J.-L.; Wang, S.-C. Total-factor energy efficiency of regions in China. Energy Policy 2006, 34, 3206-3217. [CrossRef]

42. Wang, Z.; Feng, C.; Zhang, B. An empirical analysis of China's energy efficiency from both static and dynamic perspectives. Energy 2014, 74, 322-330. [CrossRef]

43. Battese, G.E.; Rao, D.S.P.; O'Donnell, C.J. A metafrontier production function for estimation of technical efficiencies and technology gaps for firms operating under different technologies. J. Product. Anal. 2004, 21, 91-103. [CrossRef]

44. Zhou, P.; Ang, B.W.; Han, J.Y. Total factor carbon emission performance: A Malmquist index analysis. Energ. Econ. 2010, 32, 194-201. [CrossRef]

45. Färe, R.; Grosskopf, S.; Roos, P. Productivity and quality changes in Swedish pharmacies. Int. J. Prod. Econ. 1995. [CrossRef]

46. Pastor, J.T.; Lovell, C.A.K. A global Malmquist productivity index. Econ. Lett. 2005, 88, 266-271. [CrossRef]

47. An, Q.; Wu, Q.; Li, J.; Xiong, B.; Chen, X. Environmental efficiency evaluation for Xiangjiang River basin cities based on an improved SBM model and Global Malmquist index. Energy Econ. 2019, 81, 95-103. [CrossRef]

48. Shan, H. Reestimating the Capital Stock of China: 1952-2006. J. Quant. Tech. Econ. 2008, 25, 17-31.

49. Fan, M.; Shao, S.; Yang, L. Combining global Malmquist-Luenberger index and generalized method of moments to investigate industrial total factor CO2 emission performance: A case of Shanghai (China). Energy Policy 2015, 79, 189-201. [CrossRef]

50. Linn, J. Energy prices and the adoption of energy-saving technology. Econ. J. 2008, 118, 1986-2012. [CrossRef]

51. Shi, X.; Sun, S. Energy price, regulatory price distortion and economic growth: A case study of China. Energy Econ. 2017, 63, 261-271. [CrossRef]

52. Sheng, P. The explanation for the low energy efficiency of China: Allocation inefficiency or technology Inefficiency. Ind. Econ. Res. 2015, 9-20. [CrossRef]

53. Zhou, Q.; Fang, S. Regional energy endowment, firm heterogeneity, and energy efficiency: An empirical analysis based on micro industry-wide firm sample data. Econ. Sci. 2019, 66-78. [CrossRef]

54. Liu, J.; Cheng, Z.; Zhang, H. Does industrial agglomeration promote the increase of energy efficiency in China? J. Clean. Prod. 2017, 164, 30-37. [CrossRef]

55. Zhao, H.; Lin, B. Will agglomeration improve the energy efficiency in China's textile industry: Evidence and policy implications. Appl. Energy 2019, 237, 326-337. [CrossRef]

56. Mukherjee, A.; Singh, M.; Žaldokas, A. Do corporate taxes hinder innovation? J. Financ. Econ. 2017, 124, 195-221. [CrossRef]

57. Yigitcanlar, T.; Sabatini-Marques, J.; da-Costa, E.M.; Kamruzzaman, M.; Ioppolo, G. Stimulating technological innovation through incentives: Perceptions of Australian and Brazilian firms. Technol. Forecast. Soc. Chang. 2019, 146, 403-412. [CrossRef]

58. Xu, X.; Ren, X.; Chang, Z. Big Data and green development. China Ind. Econ. 2019, 5-22. [CrossRef]

59. Zheng, Q.; Lin, B. Impact of industrial agglomeration on energy efficiency in China's paper industry. J. Clean. Prod. 2018, 184, 1072-1080. [CrossRef]

60. Branca, T.A.; Fornai, B.; Colla, V.; Pistelli, M.I.; Faraci, E.L.; Cirilli, F.; Schröder, A.J. Industrial symbiosis and energy efficiency in European process Industries: A review. Sustainability 2021, 13, 9159. [CrossRef]

61. Tanaka, K.; Managi, S. Industrial agglomeration effect for energy efficiency in Japanese production plants. Energy Policy 2021, 156, 112442. [CrossRef] 